\title{
Embedment of Sensors in Ceramic Structures
}

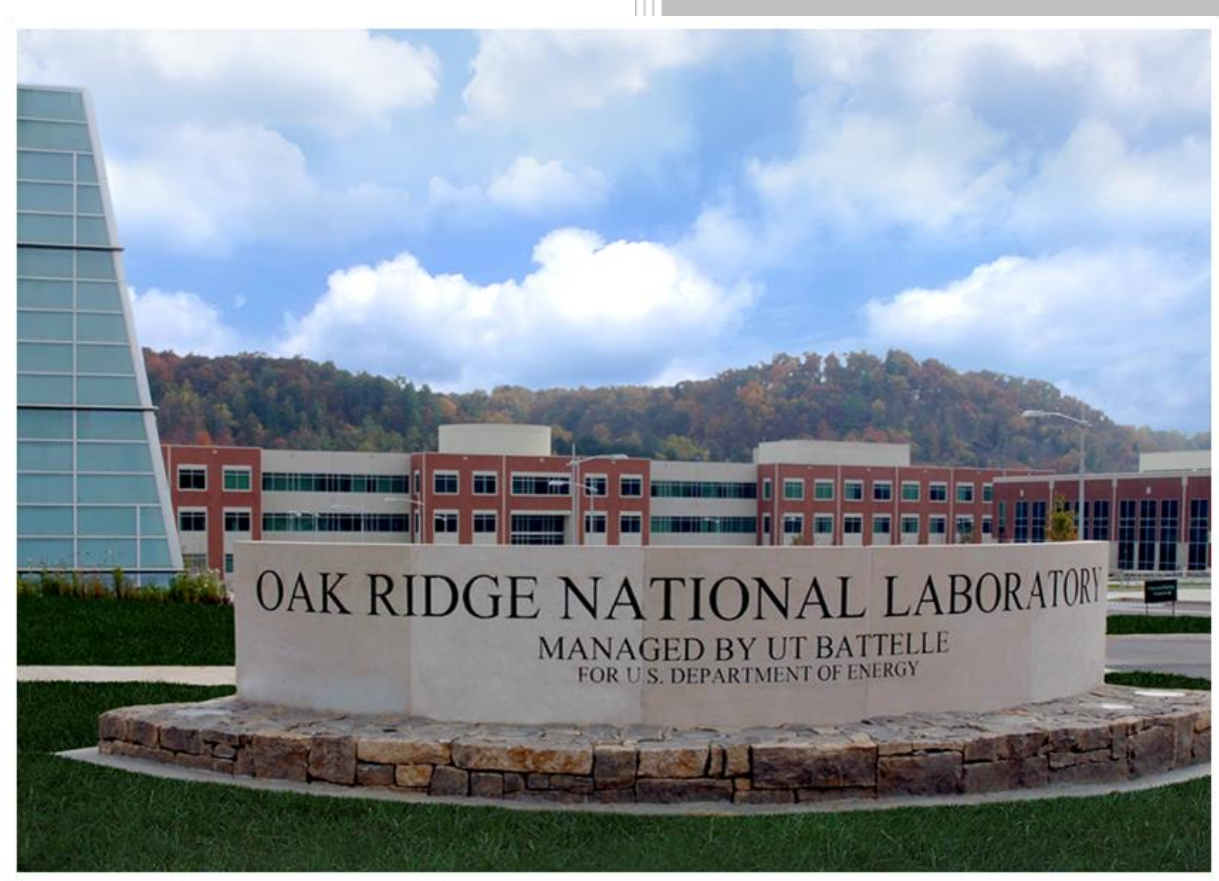

\section{Approved for public release.} Distribution is unlimited.

Christian M. Petrie Donovan N. Leonard Ying Yang Michael P. Trammel Brian C. Jolly Kurt A. Terrani

September 20, 2019 


\section{DOCUMENT AVAILABILITY}

Reports produced after January 1, 1996, are generally available free via US Department of Energy (DOE) SciTech Connect.

Website http://www.osti.gov

Reports produced before January 1, 1996, may be purchased by members of the public from the following source:

National Technical Information Service

5285 Port Royal Road

Springfield, VA 22161

Telephone 703-605-6000 (1-800-553-6847)

TDD 703-487-4639

Fax 703-605-6900

E-mail info@ntis.gov

Website http://classic.ntis.gov/

Reports are available to DOE employees, DOE contractors, Energy Technology Data Exchange representatives, and International Nuclear Information System representatives from the following source:

Office of Scientific and Technical Information

PO Box 62

Oak Ridge, TN 37831

Telephone 865-576-8401

Fax 865-576-5728

E-mail reports@osti.gov

Website http://www.osti.gov/contact.html

This report was prepared as an account of work sponsored by an agency of the United States Government. Neither the United States Government nor any agency thereof, nor any of their employees, makes any warranty, express or implied, or assumes any legal liability or responsibility for the accuracy, completeness, or usefulness of any information, apparatus, product, or process disclosed, or represents that its use would not infringe privately owned rights. Reference herein to any specific commercial product, process, or service by trade name, trademark, manufacturer, or otherwise, does not necessarily constitute or imply its endorsement, recommendation, or favoring by the United States Government or any agency thereof. The views and opinions of authors expressed herein do not necessarily state or reflect those of the United States Government or any agency thereof. 
Reactor and Nuclear Systems Division

\title{
Embedment of sensors in ceramic structures
}

\author{
Christian M. Petrie \\ Donovan N. Leonard \\ Ying Yang \\ Michael P. Trammel \\ Brian C. Jolly \\ Kurt A. Terrani
}

Date Published: September 20, 2019

Milestone \#: M3CT-19OR06090138

Prepared by

OAK RIDGE NATIONAL LABORATORY

Oak Ridge, TN 37831-6283

managed by

UT-BATTELLE, LLC

for the

US DEPARTMENT OF ENERGY

under contract DE-AC05-00OR22725 



\section{CONTENTS}

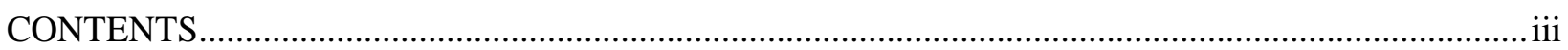

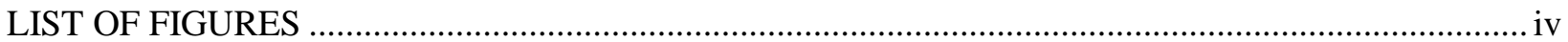

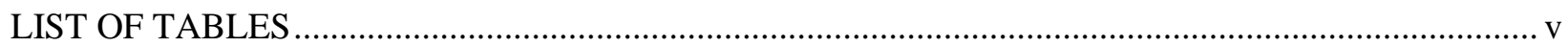

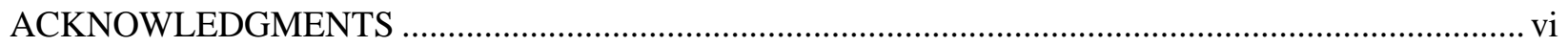

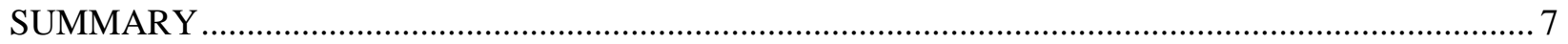

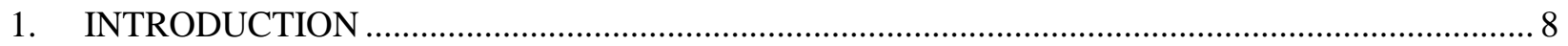

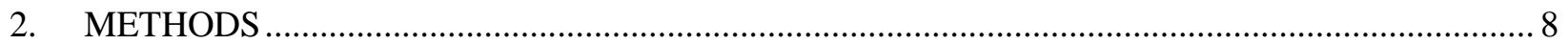

2.1 SENSORS CONSIDERED FOR EMBEDDING …...................................................... 8

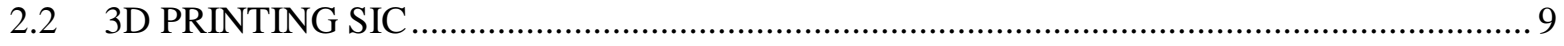

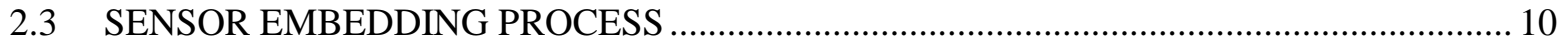

2.4 COMPUTATIONAL THERMODYNAMICS CALCULATIONS ....................................... 11

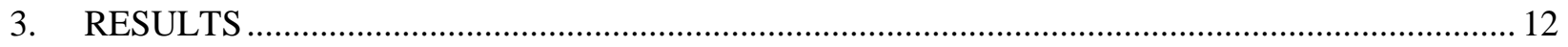

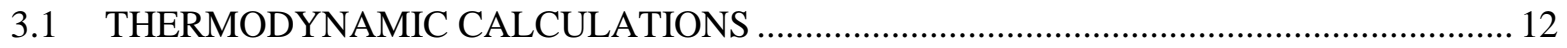

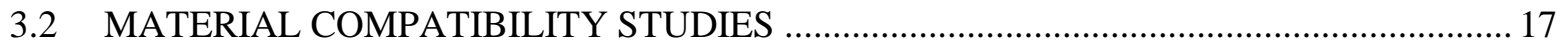

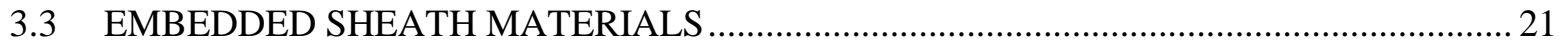

3.4 FUTURE EMBEDDING AND TESTING OF FUNCTIONAL SENSORS ........................ 23

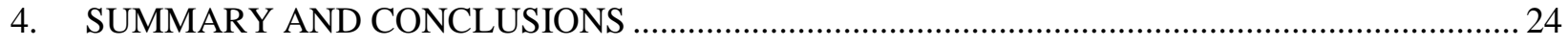

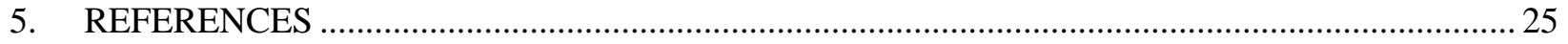




\section{LIST OF FIGURES}

Figure 1. Example showing how a ceramic part with complex geometry could be printed to incorporate sensors either before or after CVI.

Figure 2. Stable compounds in the $\mathrm{SiC}-\mathrm{HCl}-\mathrm{H}_{2}$ system at $1,000^{\circ} \mathrm{C}$ and $0.1 \mathrm{~atm}$ pressure.

Figure 3. Stable compounds in the $\mathrm{Mo}-\mathrm{HCl}-\mathrm{H}_{2}$ system at $1,000^{\circ} \mathrm{C}$ and $0.1 \mathrm{~atm}$ pressure......

Figure 4. Stable compounds in the $\mathrm{Nb}-\mathrm{HCl}-\mathrm{H}_{2}$ system at $1,000^{\circ} \mathrm{C}$ and $0.1 \mathrm{~atm}$ pressure.

Figure 5. Stable compounds in the $\mathrm{Ta}-\mathrm{HCl}-\mathrm{H}_{2}$ system at $1,000^{\circ} \mathrm{C}$ and $0.1 \mathrm{~atm}$ pressure.

Figure 6. Stable compounds in the $\mathrm{Ni}-\mathrm{HCl}-\mathrm{H}_{2}$ system at $1,000^{\circ} \mathrm{C}$ and $0.1 \mathrm{~atm}$ pressure.

Figure 7. Stable compounds in the $\mathrm{SiC}-\mathrm{HCl}-\mathrm{H}_{2}-\mathrm{Mo}$ system at $1,000^{\circ} \mathrm{C}$ and 0.1 atm pressure

Figure 8. Stable compounds in the $\mathrm{SiC}-\mathrm{HCl}-\mathrm{H}_{2}-\mathrm{Nb}$ system at $1,000^{\circ} \mathrm{C}$ and 0.1 atm pressure.

Figure 9. Stable compounds in the $\mathrm{SiC}-\mathrm{HCl}-\mathrm{H}_{2}-\mathrm{Ta}$ system at $1,000^{\circ} \mathrm{C}$ and $0.1 \mathrm{~atm}$ pressure.

Figure 10. Stable compounds in the $\mathrm{SiC}-\mathrm{HCl}-\mathrm{H}_{2}-\mathrm{Ni}$ system at $1,000^{\circ} \mathrm{C}$ and 0.1 atm pressure

Figure 11. Experimental setup for testing material compatibility during CVI.

Figure 12. W wire embedded in SiC showing (a) SEM image, (b) smaller scale SEM image of interface, (c) EDS maps for W, Si, and C, and (d) smaller scale EDS maps of W, Si, and $\mathrm{C}$ at the interface.

Figure 13. Mo wire embedded in SiC showing (a) SEM image, (b) smaller scale SEM image of interface, (c) EDS maps for Mo, Si, and C, and (d) smaller scale EDS maps of Si and $\mathrm{C}$ at the interface.

Figure 14. $\mathrm{Nb}$ wire embedded in SiC showing (a) SEM image, (b) EDS maps for $\mathrm{Nb}, \mathrm{Si}$, and $\mathrm{C}$, and (c) smaller scale EDS maps of Si and $\mathrm{C}$ at the interface.

Figure 15. Ta sheet sample embedded in SiC showing (a) SEM image and (b) EDS maps for Ta, $\mathrm{Si}$, and $\mathrm{C}$.

Figure 16. Ni wire that was ejected from the SiC matrix during CVI presented in (a) SEM image, (b) a photo of the ejected sample, and (c) EDS maps for Ni, Si, and C.

Figure 17. Au-coated $\mathrm{SiO}_{2}$ optical fibers embedded in $\mathrm{SiC}$, presented in (a, c) SEM images and (b, d) EDS maps for Au, Si, C and O....

Figure 18. Top-down picture of the sample after CVI (left), and pictures of radial and axial sections of the sample (right)

Figure 19. SEM images of the axial cross section, including the interface between the tube sample and the $\mathrm{SiC}$ matrix.

Figure 20. Mo tube embedded in SiC presented in (a) an SEM image of axial cross section, (b) EDS maps of $\mathrm{Mo}, \mathrm{Si}$, and $\mathrm{C}$ for the axial cross section, (c) an SEM image of a radial cross section, and (d) EDS maps of Mo, $\mathrm{Si}$, and $\mathrm{C}$ for the axial cross section. .23

Figure 21. Test setup for embedding functional sensors in a $\mathrm{SiC}$ ceramic matrix. 


\section{LIST OF TABLES}

Table 1. Summary of Gibbs free energies of formation for various metal chlorides............................... 11 


\section{ACKNOWLEDGMENTS}

This research was sponsored by the Transformational Challenge Reactor (TCR) Program of the US Department of Energy (DOE) Office of Nuclear Energy. The report was authored by UT-Battelle under Contract No. DE-AC05-00OR22725 with DOE. 


\section{SUMMARY}

Ceramic materials such as silicon carbide $(\mathrm{SiC})$ are attractive for many nuclear applications due to their ability to withstand high temperatures. Increasing temperature inherently improves the thermal efficiency of the power conversion cycle and can in some cases provide high-temperature process heat. SiC is particularly attractive because of its high-temperature strength retention, stability under neutron irradiation, and low neutron absorption. The Transformational Challenge Reactor (TCR) program recently demonstrated the ability to fabricate monolithic $\mathrm{SiC}$ components with complex geometries using a binder jet additive manufacturing technique followed by densification using chemical vapor infiltration (CVI). This technology presents an opportunity to embed sensors within ceramic components at critical locations that allow for enhanced process monitoring and control of advanced nuclear energy systems. The challenges with embedding sensors in ceramic components are (1) to identify appropriate materials that can survive the CVI process, (2) to ensure that sensors remain embedded after cooling to room temperature, and (3) to ensure that the sensors will be suitable for operation in a high-temperature nuclear environment. This report summarizes the sensors being considered for embedding within ceramics, the sensor embedding process, material compatibility studies, and characterization of the embedded components. Material selection is first guided by computational thermodynamics and is confirmed by embedding coupons and examining the resulting material interactions using electron microscopy. This work demonstrates that a wide range of refractory metals, as well as certain fiber optic sensors, can be successfully embedded in 3D-printed SiC. Future work will involve testing functional sensors, including thermocouples and optical fiber-based, spatially distributed temperature/strain sensors. 


\section{INTRODUCTION}

Most of the electricity produced globally results from conversion of heat to electrical energy. The Carnot cycle, which represents the ideal thermodynamic cycle to maximize the thermal efficiency of the power conversion, dictates that higher thermal efficiencies can be achieved by increasing the difference in temperature between the hot and cold "reservoirs" of the system. As such, there is a compelling motivation to increase the maximum operational temperature of the working fluid to increase the thermodynamic efficiency of the power conversion cycle. Nuclear power generation is no exception. Examples of advanced high-temperature nuclear reactor concepts include high-temperature gas-cooled reactors [1] and molten salt reactors [2]. These conceptual systems are not only more efficient, but they are also capable of providing high-temperature process heat that could be used for water desalination, oil production/refining, or hydrogen production [3].

For any high-temperature system, the structural materials must be thermodynamically stable at the operating temperatures, and they must be compatible with the surrounding materials, including the fuel and coolant. Structural materials must also maintain adequate mechanical strength at operating temperatures throughout the entire lifetime of the component. Many metals suffer from greatly reduced mechanical strength at higher temperatures. In fact, only 5 structural materials are currently codequalified by the American Society of Mechanical Engineers (ASME) for nuclear applications at temperatures above $550^{\circ} \mathrm{C}: 304$ and 316 stainless steel, Incoloy $800 \mathrm{H}, 2 \frac{1}{4} \mathrm{Cr}-1 \mathrm{Mo}$ steel, and $9 \mathrm{Cr}-1 \mathrm{Mo}-\mathrm{V}$ steel [4]. While ongoing efforts seek to use materials such as Alloy 617 at temperatures above $760^{\circ} \mathrm{C} \mathrm{[5],}$ most applications that require operating temperatures approaching or exceeding $1,000^{\circ} \mathrm{C}$ will require either refractory metals or ceramics.

The ability to fabricate structural components from ceramic materials has been limited in large part due to the inability to fabricate ceramic components in complex geometries. Recent work performed at Oak Ridge National Laboratory (ORNL), described briefly in this report, demonstrated the ability to 3D print structural ceramic components with complex geometries. This new ability makes it possible to embed sensors within the ceramic structures in locations that would not be possible to access using conventional manufacturing techniques. Embedding sensors in ceramic structures could allow for online performance monitoring to realize significant performance gains. This report summarizes ORNL's efforts to embed sensors in ceramic structures and presents specific examples of this capability relevant to nuclear energy applications.

\section{METHODS}

\subsection{SENSORS CONSIDERED FOR EMBEDDING}

In a nuclear reactor system, process parameters such as core inlet and outlet temperatures and coolant pressure can be monitored outside the core. However, if sensors can be embedded within the ceramic structures, then the ability to monitor other parameters could provide highly beneficial information regarding core and/or fuel performance. Some examples of those parameters are summarized as follows:

- Local neutron flux. The ability to measure local neutron flux near the fuel or other materials such as neutron absorbers could provide immensely useful information regarding power distribution in the reactor. This could assist in fuel management and in reducing peaking factors in the core. Self-powered neutron detectors (SPNDs) are a well-established technology for providing local power range monitoring [6] if they can be properly embedded. 
- Fuel temperature. Almost all the current operating reactors do not actively monitor fuel temperatures. Instead, measurements of the coolant inlet and outlet temperatures are combined with some measure of integral reactor power and pre-determined estimates of the core power distribution (based on the core loading) to calculate peak fuel temperatures. Direct measurements of local fuel temperatures would directly inform operators of their operating margins. Type $\mathrm{K}$ and Type $\mathrm{N}$ thermocouples have a long history of use in high-temperature reactors, so they are the primary candidates for embedded fuel temperature monitoring. Although not as welldemonstrated for nuclear applications, fiber optic temperature sensors have the potential for spatially distributed temperature measurements [7], and they have been shown to survive temperatures up to $1,000^{\circ} \mathrm{C}$ and moderate neutron fluence [8-13]. Therefore, fiber optic temperature sensors are also being considered for embedding in ceramic structures.

Understanding long-term performance in a high neutron flux application remains an active area of research [14].

- Strain. Ceramic structures can be exposed to relatively large stresses due to differential thermal expansion, particularly for large components made of ceramics with low thermal conductivity. Some ceramics such as SiC are known to swell significantly under irradiation, and the magnitude of the radiation-induced swelling is strongly dependent on both dose and temperature [15]. Therefore, these materials can also be subjected to differential swelling stresses. The ability to measure and understand these stress evolutions during irradiation could greatly improve the ability to qualify ceramic components for use in nuclear applications. Embedded spatially distributed fiber optic sensors could be used to measure strain evolution. ORNL has recently demonstrated the ability to measure strain at high temperatures by embedding metal-coated optical fibers in metal structures [16-18]. If the fibers can be successfully embedded in ceramic structures, then similar measurements may be possible. Embedded strain sensors could be used to monitor strain during irradiation testing of ceramic components or to understand and predict imminent component failure during service in a commercial reactor.

\subsection{D PRINTING SIC}

$\mathrm{SiC}$ components with complex geometries are fabricated using a binder jet printing process [19]. The powder feedstock is $>99.5 \% \alpha$-SiC from Sigma Aldrich with a particle size on the order of $20-25 \mu \mathrm{m}$. The powder is loaded into the hopper of an Innovent binder jet printer from ExOne Company of North Huntingdon, Pennsylvania. The part to be printed is first designed using a computer-aided design (CAD) package and is then sliced into layers. For each layer of the part, the printer rakes powder across the printing bed and deposits a liquid binding agent over the solid portions of the layer. The bed is lowered, and the process is repeated for the next layer. Once all layers have been printed, the entire bed is heated to $\sim 190^{\circ} \mathrm{C}$ in air to cure the binder and drive off most of the organic solvent. After curing, the green part is excavated from the powder bed, and residual powder is removed. At this point, the part is held together by the cured aqueous binder and has very low strength. The parts are then densified using chemical vapor infiltration (CVI). During this process, methyltrichlorosilane (MTS) is carried into a reactant chamber by $\mathrm{H}_{2}$ at a temperature of $\sim 1,000^{\circ} \mathrm{C}$ and a pressure of $\sim 200$ torr. As the furnace is heated prior to thermal decomposition of the MTS, the binder is volatized. The MTS infiltrates the pores in the green part and thermally decomposes to form high-purity crystalline $\mathrm{SiC}$ plus $\mathrm{HCl}$ gas. The result is a densified part ( $\sim 90 \%$ of theoretical density) composed entirely of high-purity SiC, with no significant shrinkage or distortion of the part compared to the dimensions prior to CVI. 


\subsection{SENSOR EMBEDDING PROCESS}

Sensors can be embedded by inserting the sensor into a cavity in the part and filling the gap between the sensor and the printed SiC matrix by thermal decomposition of the MTS. The binder jet process allows for printing of complex channels inside $\mathrm{SiC}$ components so that sensors can be incorporated into locations that would be otherwise impossible through traditional manufacturing techniques. There are three different approaches for fabricating the channel and inserting the sensor. In the first approach, a cavity can be printed through which the sensor can be inserted after the binder jet and CVI processes. This is the simplest approach, as it allows a sensor to be inserted, but it does not necessarily embed the sensor in the ceramic structure. In the second approach, the sensor is inserted into a printed channel after the binder jet process before the CVI process. In this case, the sensor could become embedded within the structure as $\mathrm{SiC}$ material infiltrates the gaps between the sensor and the $\mathrm{SiC}$ matrix during CVI. However, this approach requires the sensor sheath to be stiff enough to be passed through the channel without causing the sensor to break or cracking the green part before it is densified. Figure 1 shows an example of how a ceramic part with complex geometry (in this case a fueled $\mathrm{SiC}$ can) could be printed to incorporate sensors before or after CVI.

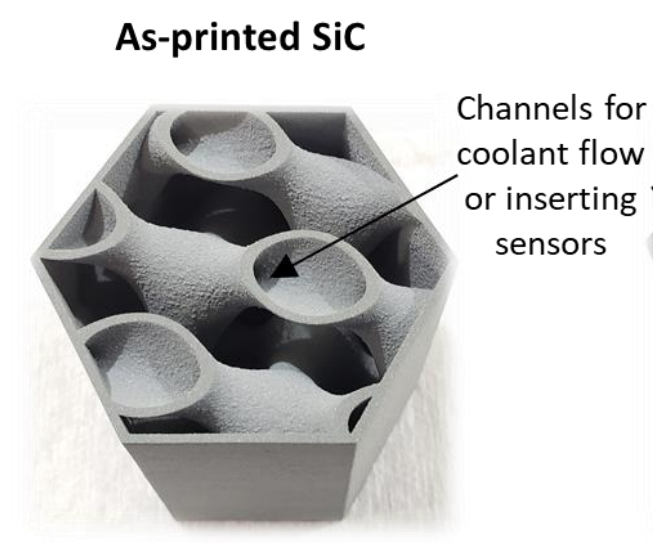

SiC loading

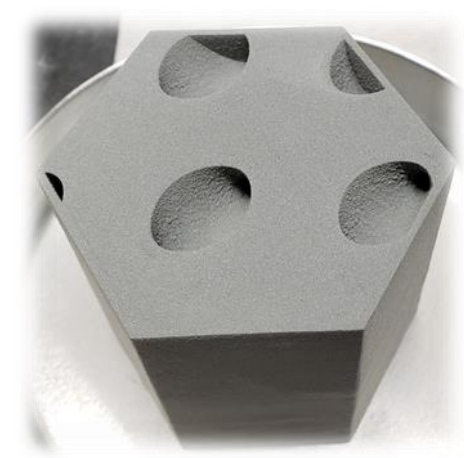

\section{Particle loading}

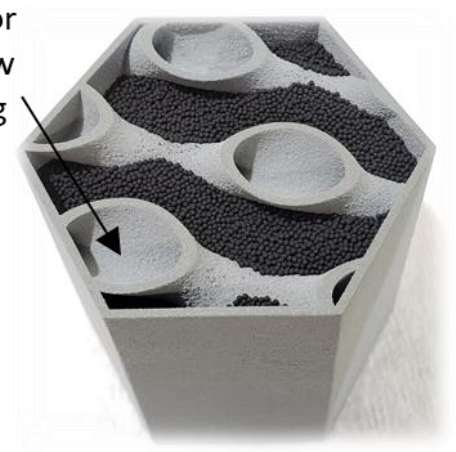

Post CVI

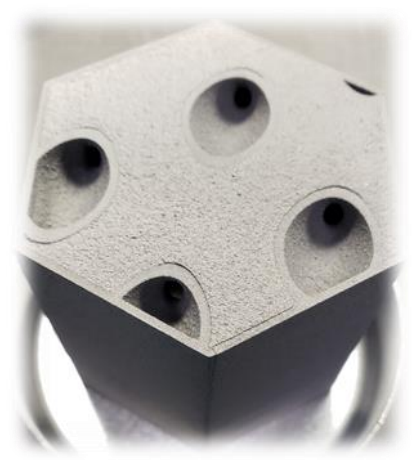

Figure 1. Example showing how a ceramic part with complex geometry could be printed to incorporate sensors either before or after CVI.

In the third approach, half of a channel is printed using the binder jet process, and then the printing process is paused while the sensor is inserted into the channel. The printing process is then resumed, and additional powder is layered on top of the sensor. This approach mitigates concerns related to breaking the sensor or cracking the part during sensor insertion, but it is limited to channels printed horizontally during the binder jet process. 


\subsection{COMPUTATIONAL THERMODYNAMICS CALCULATIONS}

The primary challenge for embedding any sensor is to identify sheath materials that can survive the high temperatures and the chemically aggressive environment of the CVI process. This year, most efforts were focused on identifying candidate sheath materials and testing their compatibility with the CVI process. As a first step toward identifying candidate sheath materials, Ellingham diagrams were consulted to determine the metals for which the standard Gibbs free energy of formation $\left(\Delta G^{0}\right)$ for metal chlorides is greater than $\Delta \mathrm{G}^{0}$ for $\mathrm{HCl}$. This would indicate that the metal is more stable than any chloride that would otherwise form. Table 1 summarizes $\Delta \mathrm{G}^{0}$ for various metal chlorides, as well as for $\mathrm{HCl}$ [20, 21].

Table 1. Summary of Gibbs free energies of formation for various metal chlorides.

\begin{tabular}{cccc}
\hline \multirow{2}{*}{ Metal } & \multirow{2}{*}{ Chloride } & \multicolumn{2}{c}{ Gibb's free energy of formation $\left.\mathbf{( k J} / \mathbf{m o l} \mathbf{C l}_{\mathbf{2}}\right)$} \\
\cline { 3 - 4 } & & $\mathbf{3 0 0} \mathbf{~}$ & $\mathbf{1 , 3 0 0 ~ \mathbf { ~ }}$ \\
\hline $\mathrm{N} / \mathrm{A}$ & $\mathrm{HCl}$ & -192 & -205 \\
\hline $\mathrm{Zr}$ & $\mathrm{ZrCl}_{4}$ & -439 & -356 \\
\hline $\mathrm{V}$ & $\mathrm{VCl}_{2}$ & -410 & -268 \\
\hline $\mathrm{Cr}$ & $\mathrm{CrCl}_{3}$ & -322 & -188 \\
\hline $\mathrm{Fe}$ & $\mathrm{FeCl}_{2}$ & -301 & -84 \\
\hline $\mathrm{Ni}$ & $\mathrm{NiCl}_{2}$ & -259 & -126 \\
\hline $\mathrm{Ta}$ & $\mathrm{TaCl}_{5}$ & -159 & -96 \\
\hline $\mathrm{Nb}$ & $\mathrm{NbCl}_{5}$ & -151 & -75 \\
\hline $\mathrm{W}$ & $\mathrm{WCl}_{6}$ & -105 & -17 \\
\hline $\mathrm{Mo}$ & $\mathrm{MoCl}_{6}$ & -88 & -13 \\
\hline $\mathrm{Pt}$ & $\mathrm{PtCl}_{2}$ & -79 & $>0$ \\
\hline $\mathrm{Au}$ & $\mathrm{AuCl}$ & -50 & $>-35$ \\
\hline
\end{tabular}

Based on the information in Table 1, the metals considered for further evaluation as sensor sheath materials are $\mathrm{Mo}, \mathrm{Nb}, \mathrm{W}, \mathrm{Ta}$, and $\mathrm{Ni}$. $\mathrm{Zr}$ and $\mathrm{V}$ have $\Delta \mathrm{G}^{0}$ values that are lower than the value for $\mathrm{HCl}$ at both $300 \mathrm{~K}$ and $1300 \mathrm{~K}$. Fe, $\mathrm{Cr}$, and $\mathrm{Ni}$ have $\Delta \mathrm{G}^{0}$ values that are higher than the value for $\mathrm{HCl}$ at 1,300 K, but lower than the value for $\mathrm{HCl}$ at $300 \mathrm{~K}$. Therefore, these materials are not ideal candidates as they could form chloride compounds if the part is exposed to $\mathrm{HCl}$ at lower temperatures. $\mathrm{Ni}$ is still being considered because $\mathrm{Ni}$ and $\mathrm{Au}$ are the only commercially available metal coatings for optical fibers that can survive temperatures in the range of $\sim 1,000^{\circ} \mathrm{C}$. Au-coated optical fiber-based sensors are also being considered due to the high $\Delta \mathrm{G}^{0}$ value for $\mathrm{AuCl}$. However, the CVI temperatures are close to the melting point of $\mathrm{Au}\left(1,064^{\circ} \mathrm{C}\right)$, so there is some risk that the Au coating could melt during the CVI process. Pt is not being considered due to its extremely high cost. 
Computational thermodynamic calculations were performed to assess the compatibility of candidate sheath materials with both $\mathrm{HCl}$ and $\mathrm{SiC}$ at temperatures in the range of $1,000^{\circ} \mathrm{C}$. The FactSage 7.2 software package, which uses the well-established CALPHAD approach [22], was used with the Factps database to determine the stable compounds that form when exposing a system containing $\mathrm{SiC}$ and $1,000 \mathrm{ppm}$ of various metals to both $\mathrm{H}_{2}$ and $\mathrm{HCl}$ at $1,000^{\circ} \mathrm{C}$. The partial pressures of $\mathrm{H}_{2}$ and $\mathrm{HCl}$ were varied, but the total system pressure was maintained at 0.1 atm.

\section{RESULTS}

\subsection{THERMODYNAMIC CALCULATIONS}

The results of the thermodynamic calculations are presented in Figure 2 through Figure 6 . These figures show the stable compounds that will form at a temperature of $1,000^{\circ} \mathrm{C}$ and a total pressure of $0.1 \mathrm{~atm}$ as a function of the partial pressures of $\mathrm{HCl}$ and $\mathrm{H}_{2}$. Figure 2 shows the range of partial pressures under which solid $\mathrm{SiC}$ will form during the CVI process. The furnace will not be operated under high $\mathrm{HCl}$ partial pressures and low $\mathrm{H}_{2}$ partial pressures (bottom right portion of the figure), because this will result in the formation of carbon + gaseous reaction products and unsuccessful densification of the $\mathrm{SiC}$ component. MTS is carried into the furnace by $\mathrm{H}_{2}$ with a nominal $\mathrm{H}_{2}$ :MTS ratio of 10:1. Therefore, if all of the MTS thermally decomposes to form $\mathrm{HCl}$ ( 3 moles of $\mathrm{HCl}$ per 1 mole of MTS), the minimum $\mathrm{H}_{2}: \mathrm{HCl}$ ratio would be 10:3, which would give partial pressures of 0.08 and 0.02 atm for $\mathrm{H}_{2}$ and $\mathrm{HCl}$, respectively. This combination is safely within the region where $\mathrm{SiC}$ does not form gaseous compounds.

Figure 3 through Figure 6 show the same data for various metals in $\mathrm{HCl}$ and $\mathrm{H}_{2}$. These figures show that for the range of desired $\mathrm{HCl}$ and $\mathrm{H}_{2}$ partial pressures, all the metals evaluated are stable and do not form chloride compounds. Tungsten was not specifically evaluated in these calculations, but several components inside the CVI furnace use a tungsten wire mesh. Therefore, there is physical evidence that tungsten does not react prohibitively with $\mathrm{HCl}$ during the CVI process.

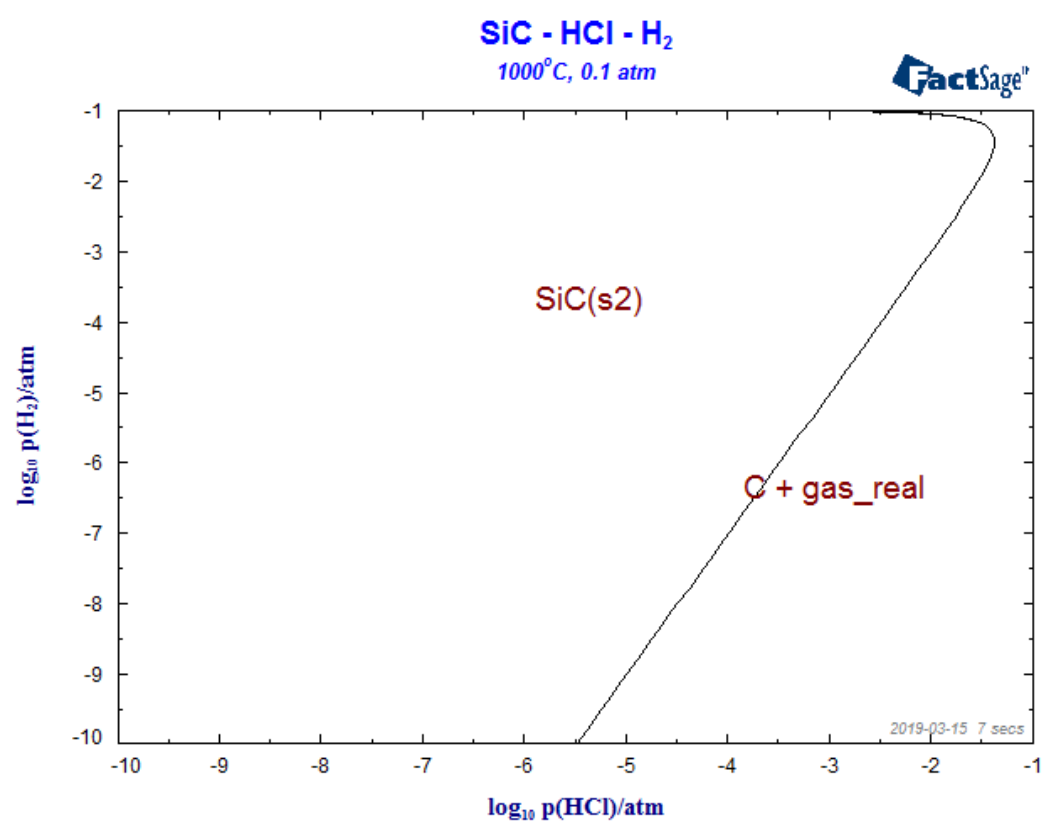

Figure 2. Stable compounds in the $\mathrm{SiC}-\mathrm{HCl}-\mathrm{H}_{2}$ system at $1,000^{\circ} \mathrm{C}$ and 0.1 atm pressure. 


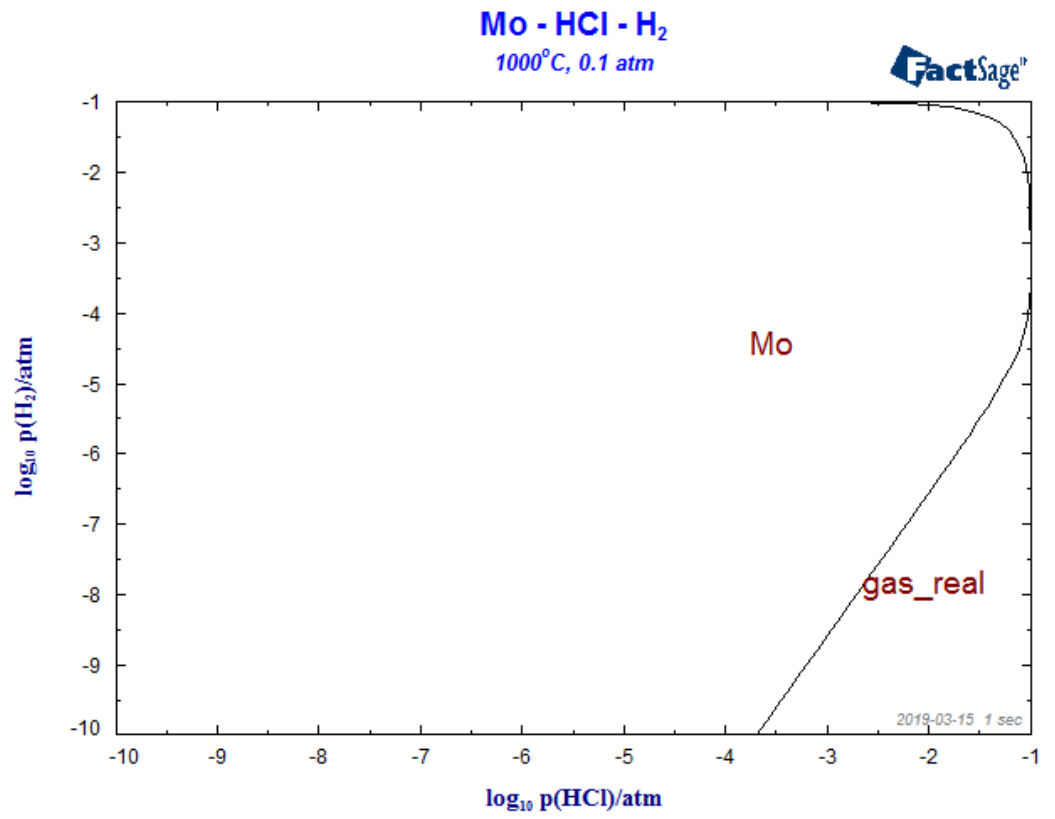

Figure 3. Stable compounds in the $\mathrm{Mo}-\mathrm{HCl}-\mathrm{H}_{2}$ system at $1,000^{\circ} \mathrm{C}$ and 0.1 atm pressure.

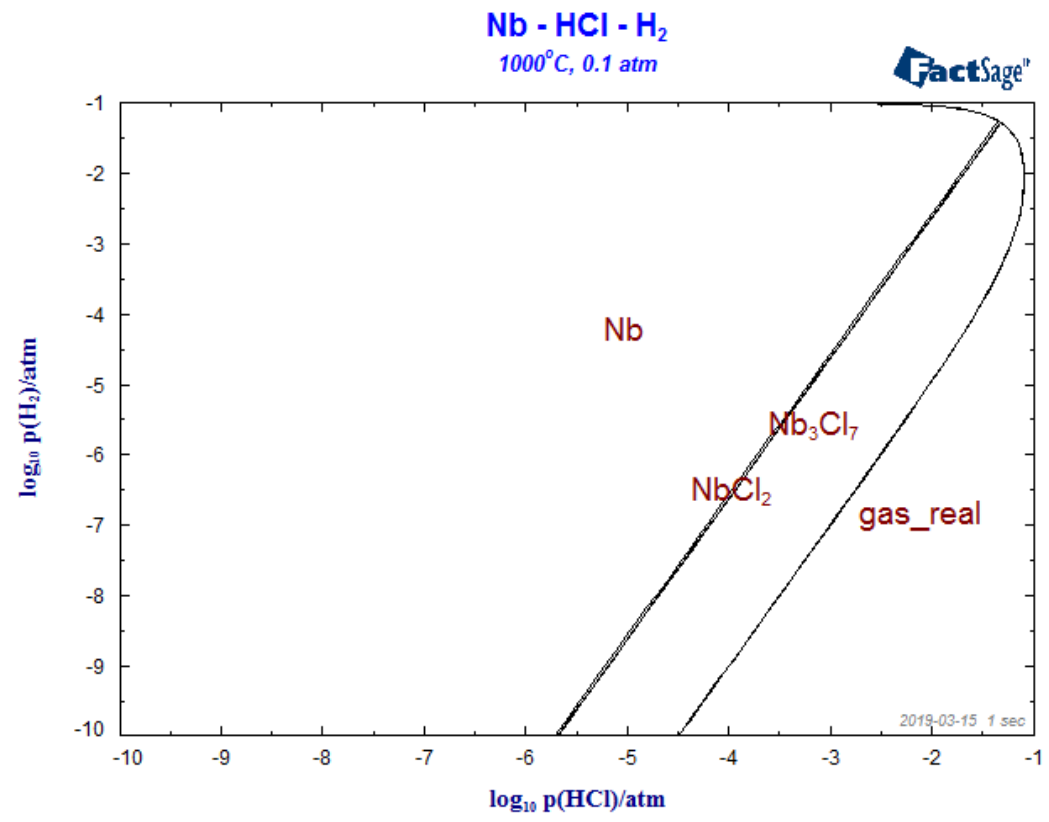

Figure 4. Stable compounds in the $\mathrm{Nb}-\mathrm{HCl}-\mathrm{H}_{2}$ system at $1,000^{\circ} \mathrm{C}$ and $0.1 \mathrm{~atm}$ pressure. 


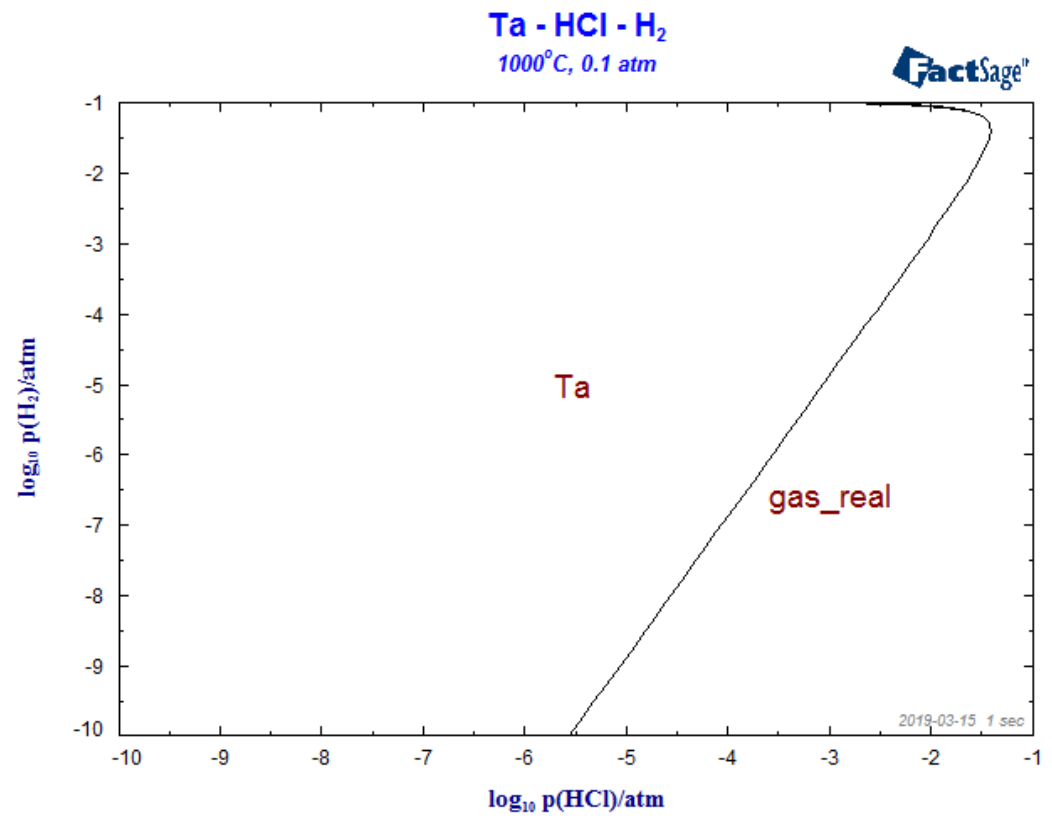

Figure 5. Stable compounds in the $\mathrm{Ta}-\mathrm{HCl}-\mathrm{H}_{2}$ system at $1,000^{\circ} \mathrm{C}$ and 0.1 atm pressure.

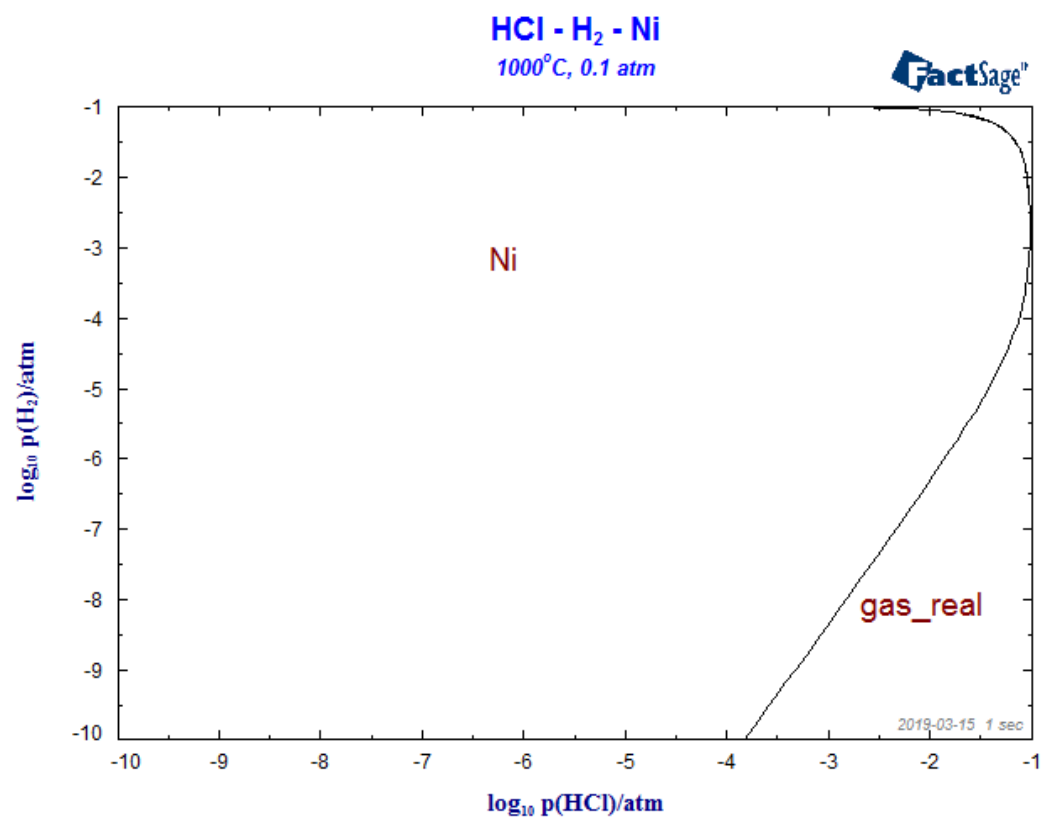

Figure 6. Stable compounds in the $\mathrm{Ni}-\mathrm{HCl}-\mathrm{H}_{2}$ system at $1,000^{\circ} \mathrm{C}$ and $0.1 \mathrm{~atm}$ pressure. 
The results presented in the figures above provide additional evidence that the refractory metals that were evaluated in the thermodynamic calculations ( $\mathrm{Mo}, \mathrm{Nb}, \mathrm{Ta}$, and $\mathrm{Ni}$ ) or tested experimentally $(\mathrm{W})$ will not suffer prohibitive reactions with $\mathrm{HCl}$ during CVI. However, there is also some concern that the metals could react with the $\mathrm{SiC}$ matrix. Based on the phase diagrams, many of these metals will likely form metal carbides and/or silicides. This may be acceptable if the reactions do not result in the formation of gaseous compounds that would prevent the sensor sheaths from being embedded in the SiC matrix. In addition, the dynamics of the diffusion-limited reactions with the $\mathrm{SiC}$ matrix may be slow enough that the reaction layer is limited to a very thin region at the surface of the sensor sheath. Figure 7 through Figure 10 show the stable compounds that form in the $\mathrm{SiC}-\mathrm{HCl}-\mathrm{H}_{2}-\mathrm{M}$ system, in which $\mathrm{M}$ is the refractory metal of interest. These figures show similar trends to the previous figures in that no gaseous reaction products are formed over the range of desired $\mathrm{HCl}$ and $\mathrm{H}_{2}$ partial pressures. However, carbide and silicide compounds are expected to form in all the metal sheaths. As mentioned previously, this is not necessarily a problem depending on the size of the interaction layer.

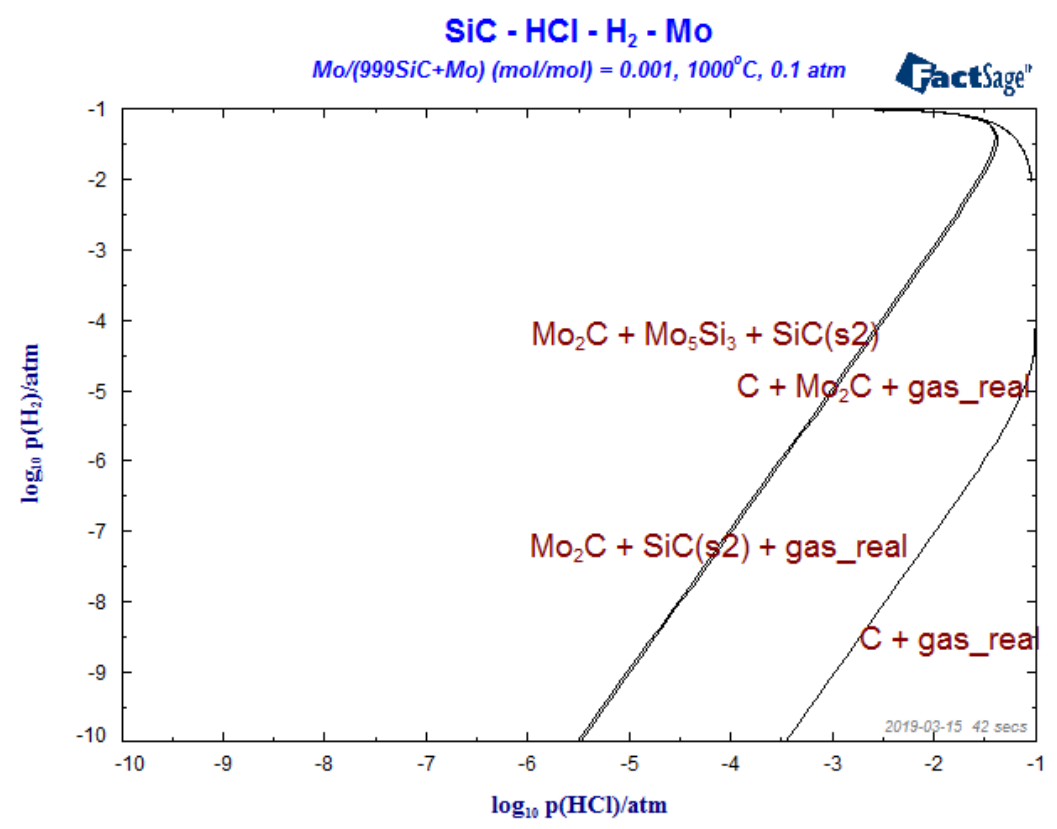

Figure 7. Stable compounds in the $\mathrm{SiC}-\mathrm{HCl}-\mathrm{H}_{2}-\mathrm{Mo}$ system at $1,000^{\circ} \mathrm{C}$ and $0.1 \mathrm{~atm}$ pressure. 


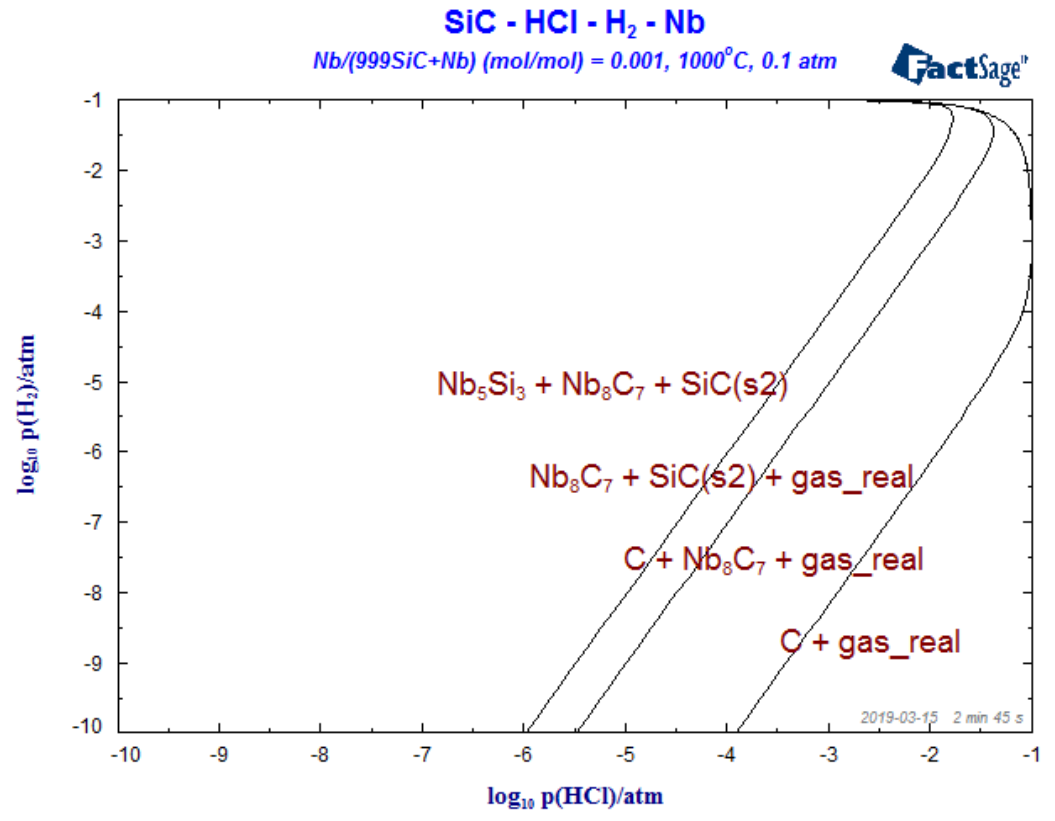

Figure 8. Stable compounds in the $\mathrm{SiC}-\mathrm{HCl}-\mathrm{H}_{2}-\mathrm{Nb}$ system at $1,000^{\circ} \mathrm{C}$ and $0.1 \mathrm{~atm}$ pressure.

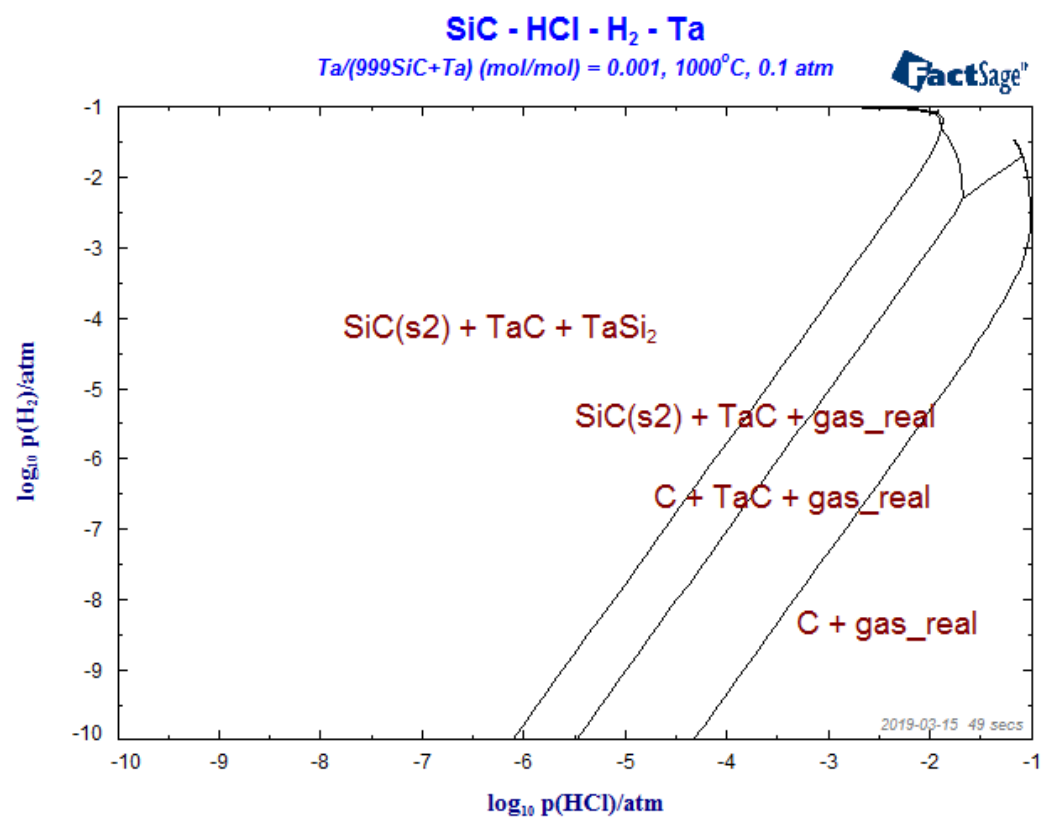

Figure 9. Stable compounds in the SiC-HCl-H2-Ta system at $1,000^{\circ} \mathrm{C}$ and 0.1 atm pressure. 


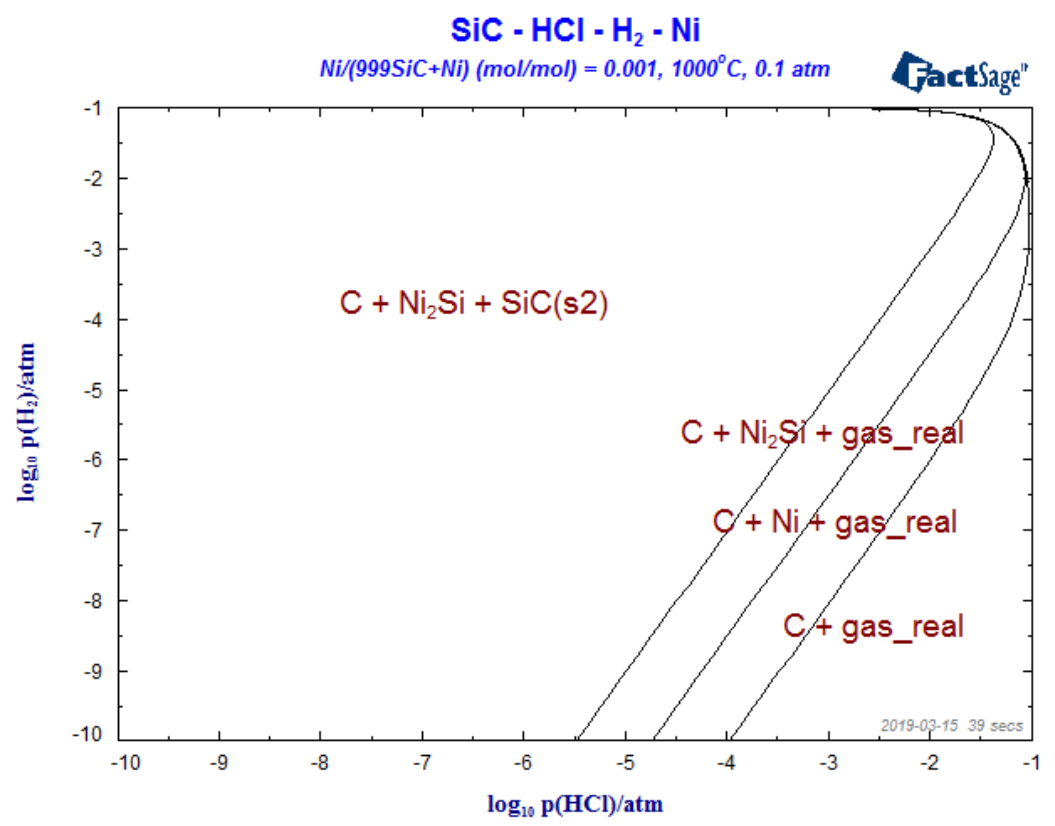

Figure 10. Stable compounds in the $\mathrm{SiC}-\mathrm{HCl}-\mathrm{H}_{2}-\mathrm{Ni}$ system at $1,000^{\circ} \mathrm{C}$ and $0.1 \mathrm{~atm}$ pressure.

\subsection{MATERIAL COMPATIBILITY STUDIES}

The computational thermodynamic calculations presented in Section 3.1 provide confidence that refractory metals can survive the CVI process and be successfully embedded in a SiC ceramic structure. To confirm this, material samples in the form of wires or thin sheets were placed inside a printed SiC can filled with loose $\mathrm{SiC}$ powder. The samples included were composed of $\mathrm{W}, \mathrm{Mo}, \mathrm{Nb}, \mathrm{Ta}$, and $\mathrm{Ni}$. In addition, short sections of $\mathrm{Au}$-coated $\mathrm{SiO}_{2}$ optical fiber were included. The loading of the cans is shown in Figure 11. The cans were then placed inside the CVI furnace for densification. After CVI, the parts were sectioned for microscopy to evaluate the metal/ceramic interface and to identify any chemical interactions that occurred. Scanning electron microscopy (SEM) was used to characterize the interface with energy-dispersive $\mathrm{x}$-ray spectroscopy (EDS) mapping to indicate elemental distributions within the samples. Figure 12 through Figure 17 show the microscopy results for all specimens. 


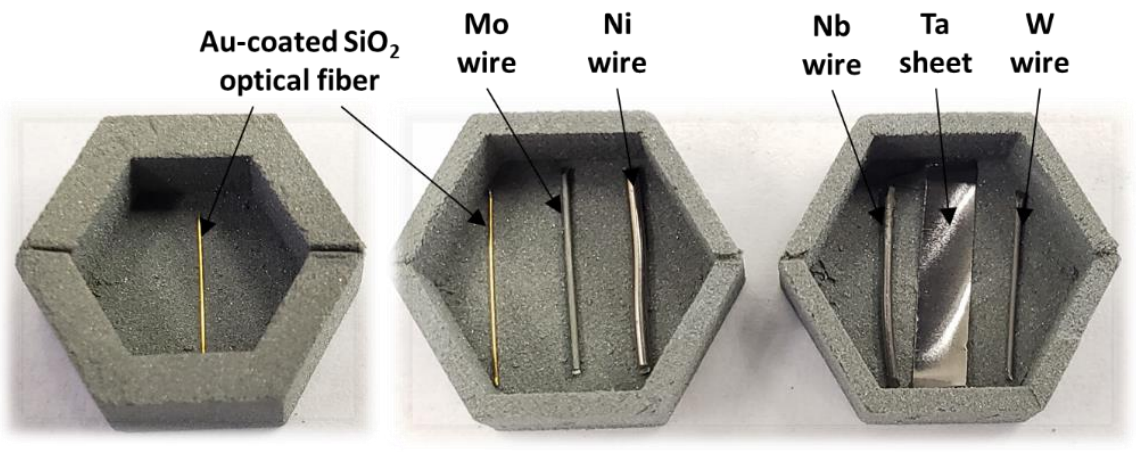

Loading samples in SiC cans

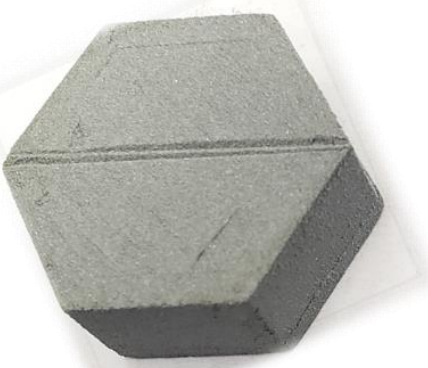

Filling cans with SiC powder

Figure 11. Experimental setup for testing material compatibility during CVI.
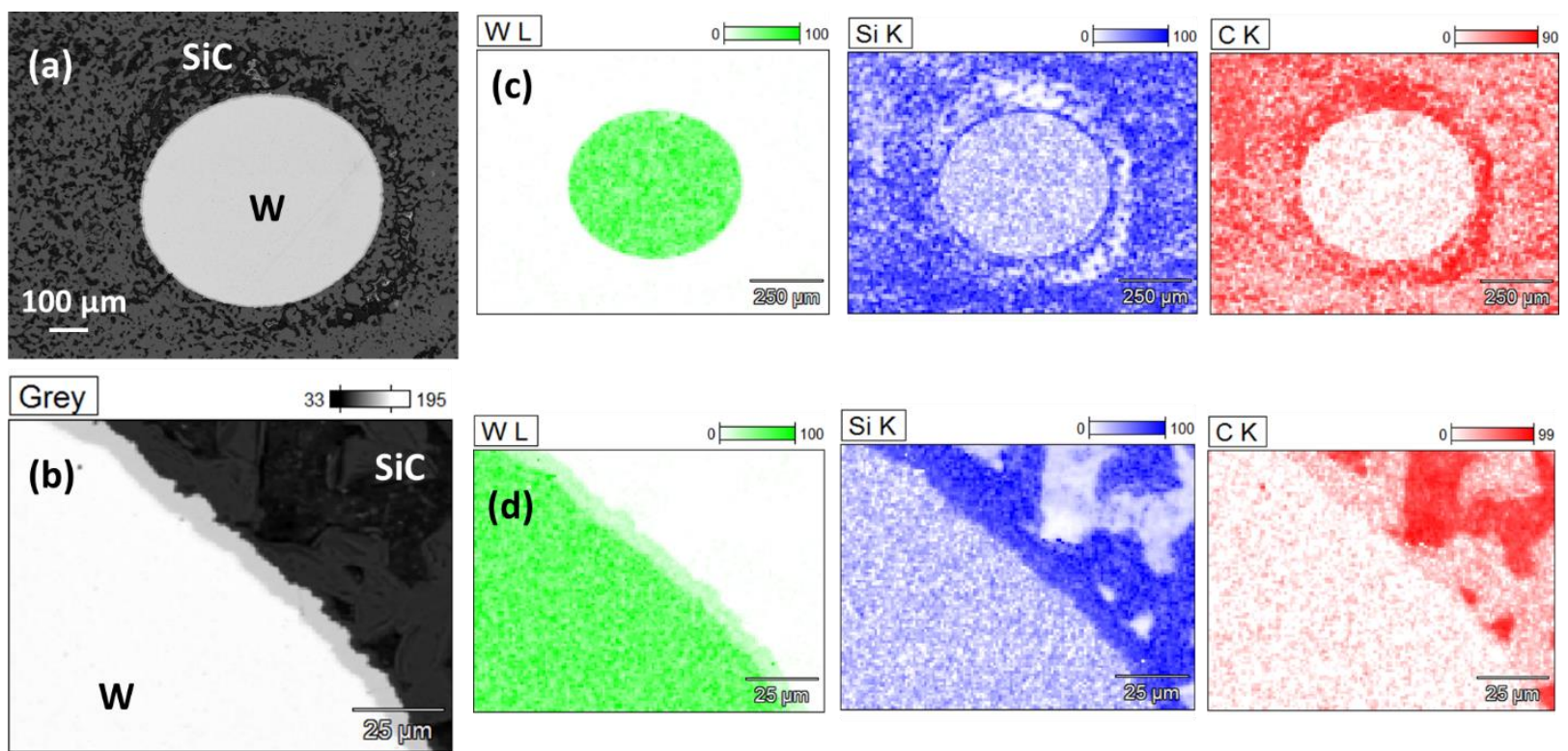

Figure 12. W wire embedded in SiC showing (a) SEM image, (b) smaller scale SEM image of interface, (c) EDS maps for $\mathrm{W}, \mathrm{Si}$, and $\mathrm{C}$, and (d) smaller scale EDS maps of $\mathrm{W}, \mathrm{Si}$, and $\mathrm{C}$ at the interface. 

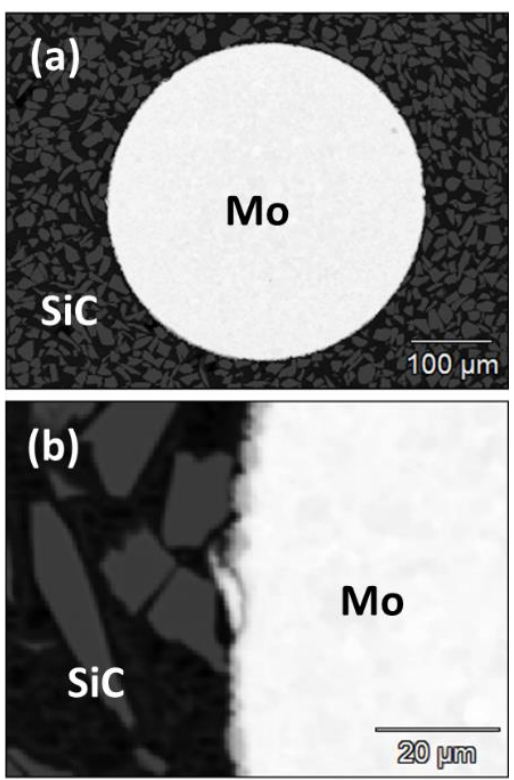
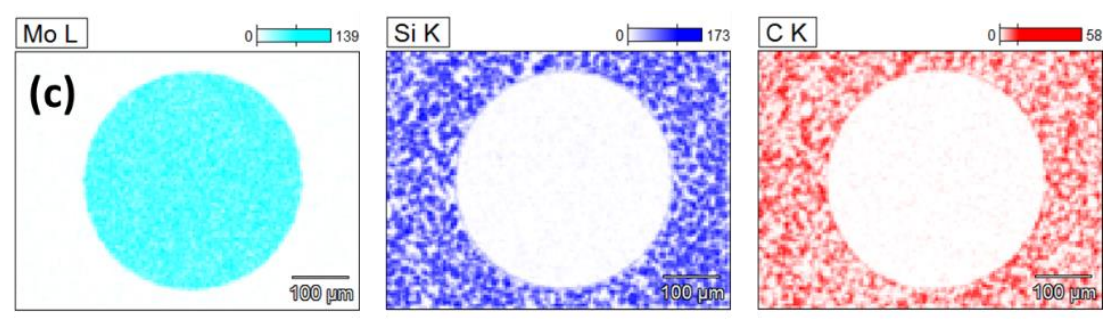

(d)
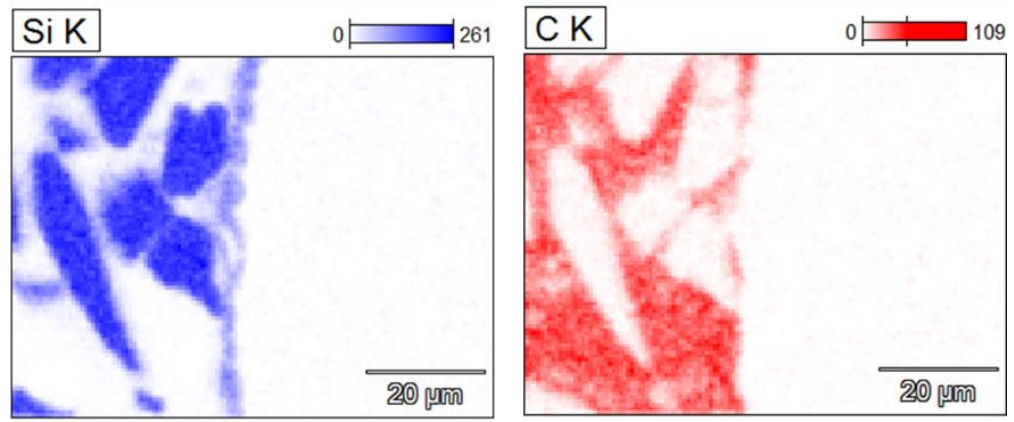

Figure 13. Mo wire embedded in SiC showing (a) SEM image, (b) smaller scale SEM image of interface, (c) EDS maps for Mo, Si, and $\mathrm{C}$, and (d) smaller scale EDS maps of Si and $\mathrm{C}$ at the interface.
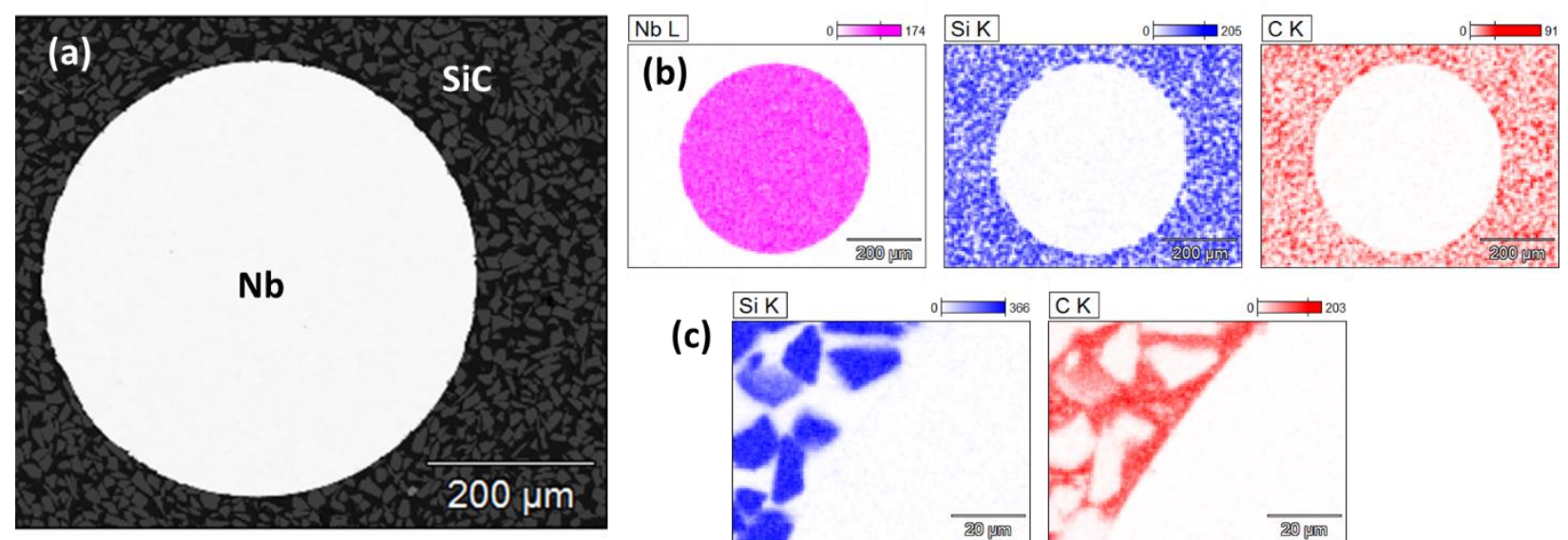

(c)
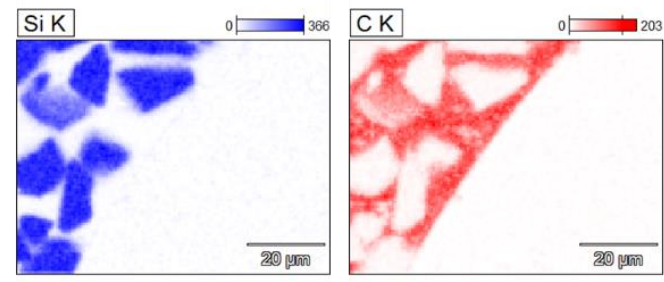

Figure 14. Nb wire embedded in $\mathrm{SiC}$ showing (a) SEM image, (b) EDS maps for $\mathrm{Nb}$, $\mathrm{Si}$, and $\mathrm{C}$, and (c) smaller scale EDS maps of $\mathrm{Si}$ and $\mathrm{C}$ at the interface.

Figure 12 through Figure 14 show that the W, Mo, and Nb specimens clearly survive the embedding process. There is some chemical interaction between the metals and the surrounding SiC matrix, which was expected based on the results of the thermodynamic calculations. However, the interaction layer is on the order of $\mu \mathrm{m}$, indicating that the dynamics of the diffusion-limited reaction are quite slow.

Furthermore, the interface between the metals and the matrix appears to show strong bonding, indicating that these materials are strong candidates for use in sensor sheath materials. 
Figure 15 shows that the Ta specimen was also successfully embedded in the $\mathrm{SiC}$ matrix. However, the EDS maps show that significant silicon content is present within the entire $\sim 20 \mu \mathrm{m}$ thick sample. It is unclear what the size of the chemical interaction layer might be for a thicker sample that is more representative of a sensor sheath. However, it is clear that the interaction layer is much thicker than that of the $\mathrm{W}, \mathrm{Mo}, \mathrm{Nb}$ samples; therefore, Ta is not being considered as a primary candidate for a sensor sheath material.
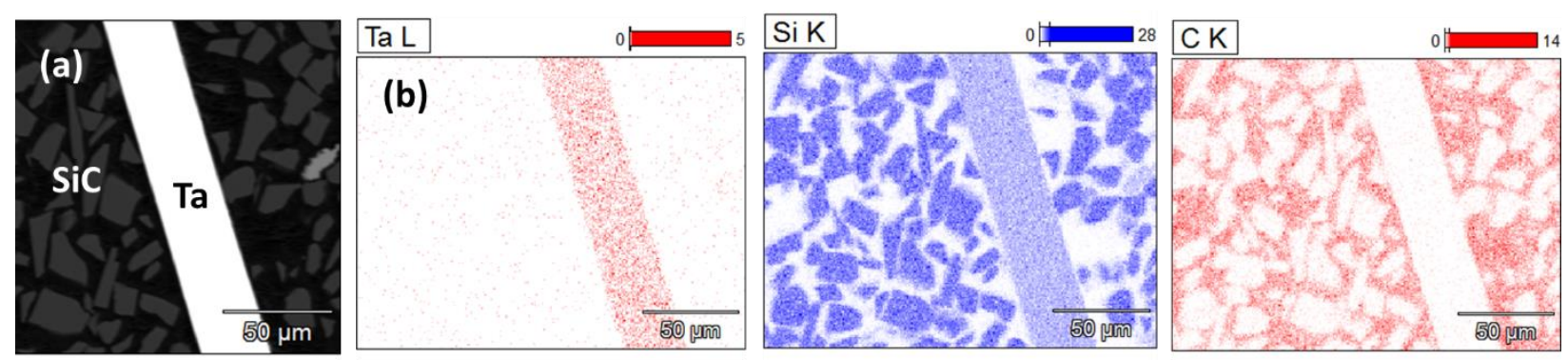

Figure 15. Ta sheet sample embedded in SiC showing (a) SEM image and (b) EDS maps for Ta, Si, and C.

Figure 16 shows that the Ni sample suffered a severe reaction during CVI. The sample was ejected from the $\mathrm{SiC}$ can and showed a black appearance after being removed from the CVI furnace. Comparing the $\Delta \mathrm{G}^{0}$ values for $\mathrm{NiCl}_{2}$ (see Table 1) to those for $\mathrm{HCl}$ shows that $\mathrm{NiCl}_{2}$ should not form. EDS mapping of the $\mathrm{Cl}$ content (not shown) did not reveal any obvious signs of chloride formation in the sample. In any case, Ni-based sensor sheaths are not being considered due to the violent reaction that the Ni sample exhibited.
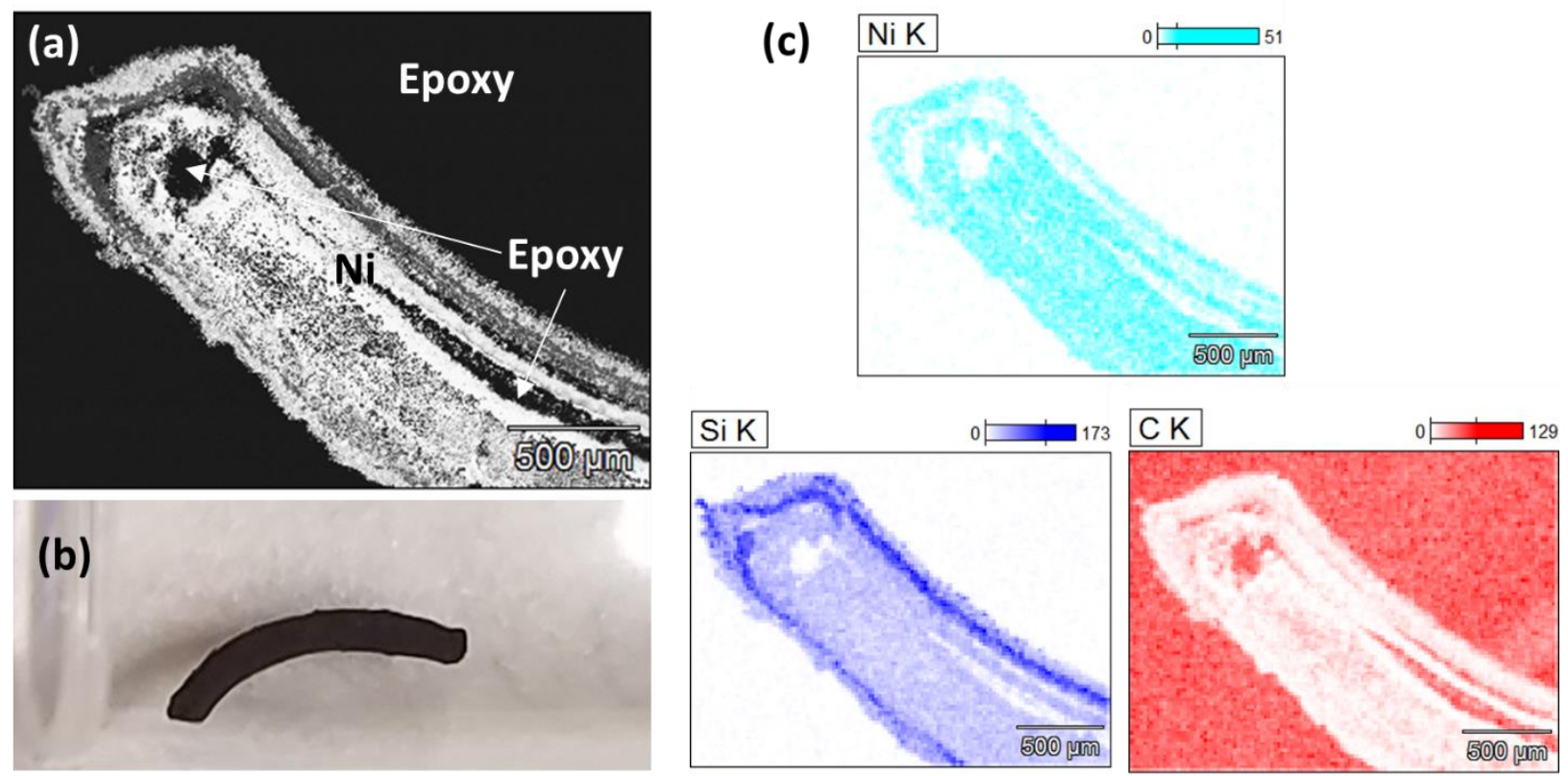

Figure 16. Ni wire that was ejected from the SiC matrix during CVI presented in (a) SEM image, (b) a photo of the ejected sample, and (c) EDS maps for $\mathrm{Ni}, \mathrm{Si}$, and $\mathrm{C}$. 
The last samples that were embedded were Au-coated $\mathrm{SiO}_{2}$ optical fibers. The fibers appear to be successfully embedded in the $\mathrm{SiO}_{2}$ matrix. However, the Au coating is clearly deformed and may have melted during the $\mathrm{CVI}$ process. The melting point of $\mathrm{Au}$ is $1,064^{\circ} \mathrm{C}$. While the furnace was operated at a nominal temperature of $1,000^{\circ} \mathrm{C}$, there could be temperature variations within the furnace or exothermic chemical reactions that contribute to heating within the samples that could have caused the temperature of the coating to exceed the melting point of Au. In any case, even after the Au coating melted, the uncoated $\mathrm{SiO}_{2}$ optical fiber did not show significant degradation when exposed to $\mathrm{HCl}$. In both samples, there is no significant amount of $\mathrm{C}$ or Au within the fiber (only Si and O). Future testing of polymer-coated fibers will confirm whether the fiber can survive without the Au coating. The polymer will be vaporized at much lower temperatures (on the order of $400^{\circ} \mathrm{C}$ ), but the hope is that $\mathrm{SiC}$ will be deposited on the surface of the fiber during CVI, thus embedding the fiber within the $\mathrm{SiC}$ matrix.

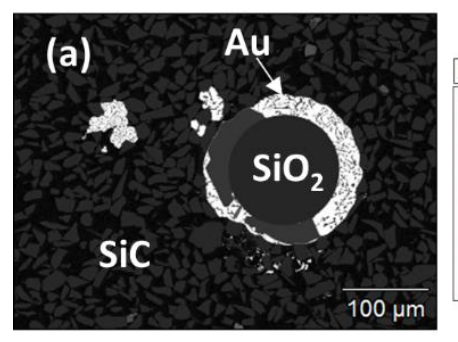

(b)

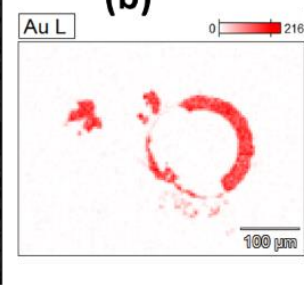

(d)
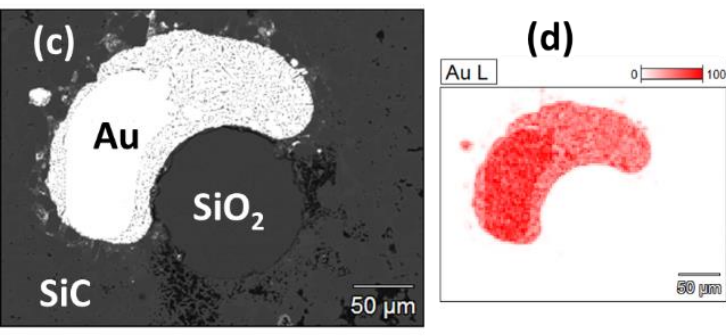
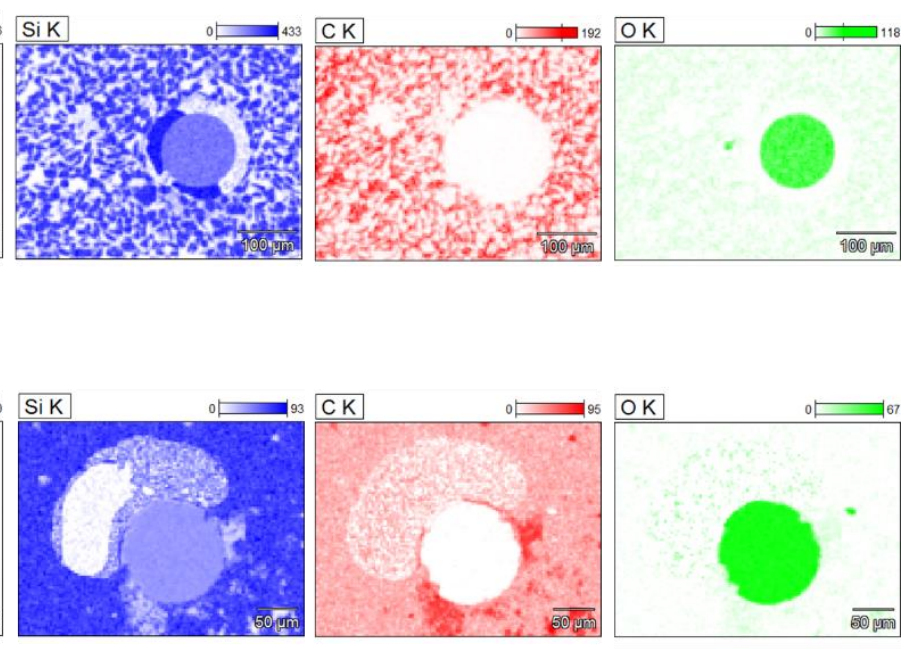

Figure 17. Au-coated $\mathrm{SiO}_{2}$ optical fibers embedded in $\mathrm{SiC}$, presented in (a, c) $\mathrm{SEM}$ images and (b, d) EDS maps for $\mathrm{Au}, \mathrm{Si}, \mathrm{C}$ and $\mathrm{O}$.

\subsection{EMBEDDED SHEATH MATERIALS}

The next test performed was embedding a more representative sensor sheath geometry. For this, a $\Phi 1.6 \mathrm{~mm}\left({ }^{1} / 16\right.$-inch $) \times 0.3 \mathrm{~mm}(0.012$-inch $)$ Mo tube section was embedded within a 3D-printed SiC block. The block was printed with a central hole in which the Mo tube was inserted prior to CVI. After CVI, the part was sectioned for microscopy as was done for the material compatibility samples. Figure 18 shows a top-down picture of the sample after CVI, as well as pictures of radial and axial sections of the sample. Figure 19 shows SEM images of the axial cross section, including the interface between the tube sample and the $\mathrm{SiC}$ matrix. These figures show that the tube was successfully embedded, although the interface between the tube and the $\mathrm{SiC}$ matrix shows some regions where bonding has occurred and others where there is no bonding. Cracks are also visible. It is not surprising that the tube is not perfectly bonded to the matrix. The bonding occurs at a temperature of approximately $1,000^{\circ} \mathrm{C}$. As the part cools to room temperature, the Mo tube contracts much more than the $\mathrm{SiC}$ matrix due to the difference in coefficients of thermal expansion. The approximate differential thermal strain is calculated to be $0.14 \%$, which amounts to a stress on the order of hundreds of MPa. This stress is enough to exceed the strength of the interface and cause cracking or debonding to occur. However, except for strain sensors, most sensors do not require that the sensor sheath be perfectly bonded to the surrounding material. 

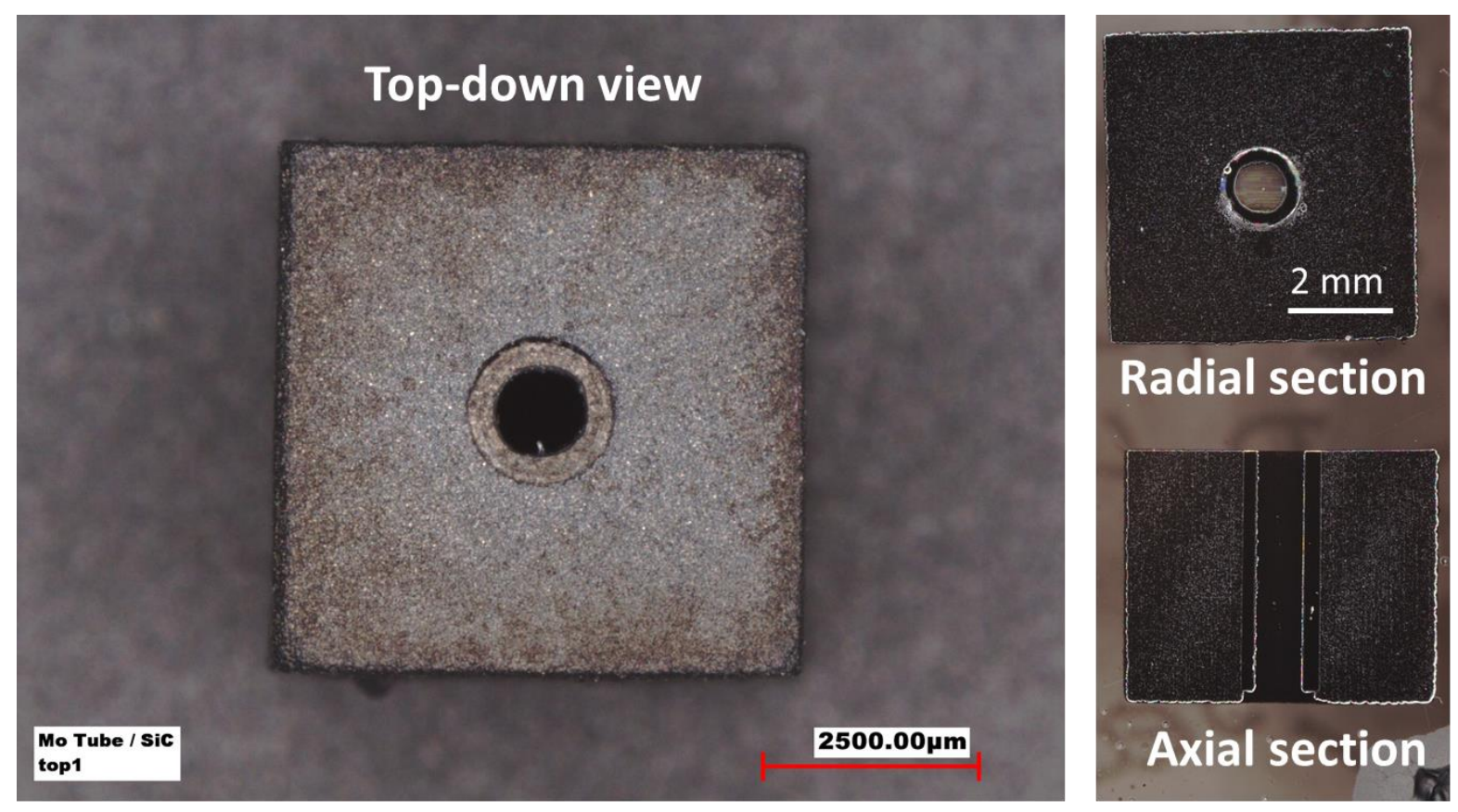

Figure 18. Top-down picture of the sample after CVI (left), and pictures of radial and axial sections of the sample (right).

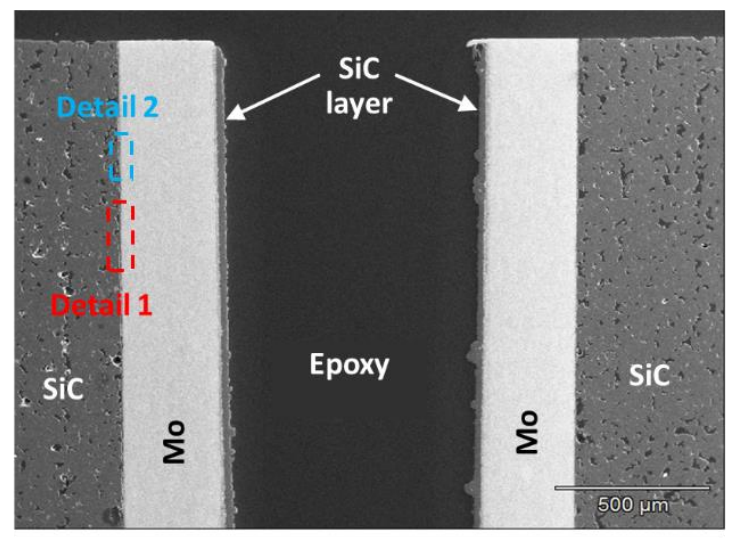

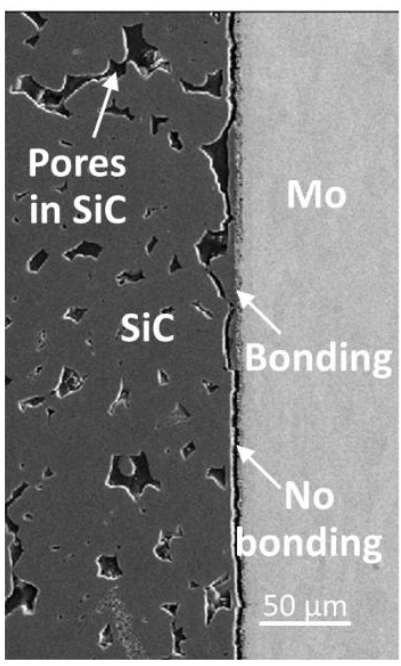

Detail 1

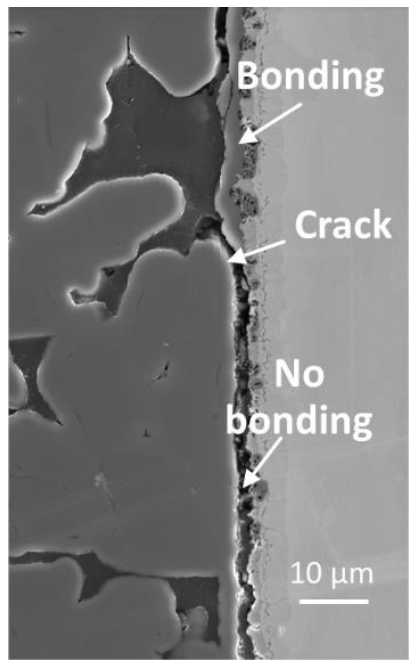

Detail 2

Figure 19. SEM images of the axial cross section, including the interface between the tube sample and the $\mathrm{SiC}$ matrix.

Figure 20 shows EDS maps of the radial and axial cross sections. The sample was mounted in epoxy, and some of the epoxy can be clearly seen in the EDS maps and on the optical images in Figure 18, particularly in the radial section. Besides the regions affected by the epoxy, the remainder of the tube appears to be largely unaffected by the CVI process. A thin SiC layer was deposited on the inside of the tube because the tube was not sealed. There is a very thin (on the order of a few $\mu \mathrm{m}$ ) $\mathrm{Mo} / \mathrm{C}$ interaction layer, and a slightly thicker (closer to $5 \mu \mathrm{m}$ ) $\mathrm{Mo} / \mathrm{Si}$ interaction layer. However, compared to the thickness of the tube $(300 \mu \mathrm{m})$, this layer is not significant. 

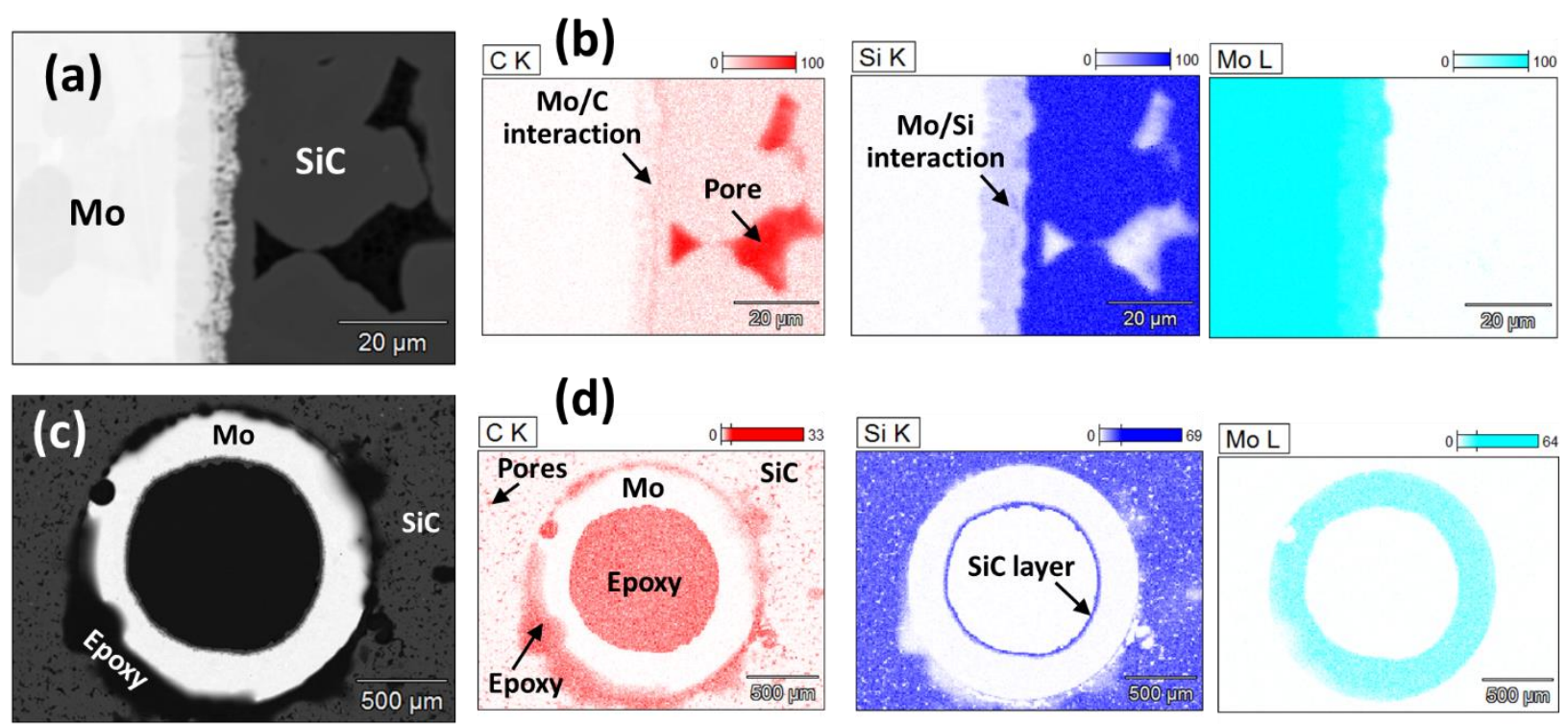

Figure 20. Mo tube embedded in SiC presented in (a) an SEM image of axial cross section, (b) EDS maps of $\mathrm{Mo}, \mathrm{Si}$, and $\mathrm{C}$ for the axial cross section, (c) an SEM image of a radial cross section, and

(d) EDS maps of Mo, $\mathrm{Si}$, and $\mathrm{C}$ for the axial cross section.

\subsection{FUTURE EMBEDDING AND TESTING OF FUNCTIONAL SENSORS}

The successful embedding of a Mo tube provides high confidence that thermocouples, SPNDs, and spatially distributed fiber optic temperature sensors with Mo sheaths can be successfully embedded in SiC ceramic components. $\mathrm{SiO}_{2}$ fiber optics also appear to be able to survive the CVI process. Therefore, the next step is to embed functional sensors in a SiC component. The first test will embed Mo-sheathed Type $\mathrm{C}$ thermocouples, Mo-sheathed optical fibers (for spatially distributed temperature measurements), and unsheathed optical fibers (for spatially distributed strain measurements). Nb-sheathed thermocouples such as the high-temperature irradiation-resistant thermocouples (HTIR TCs) developed at the Idaho National Laboratory (INL) [23], are also candidates for embedding and will be considered in future tests. The testing setup is shown in Figure 21. The sensors and/or sensor sheaths (in the case of fiber optics) will be inserted into cavities in the 3D-printed $\mathrm{SiC}$ matrix prior to CVI. The sheaths will pass up through the feedthroughs in the flange of the CVI furnace. This will first require cutting the connectors of the fiber optic sensors and removing the connectors of the thermocouple so that the leads can fit through the feedthroughs. The connectors will be rejoined before the furnace is powered so that measurements can be made before, during, and after CVI. The thermocouple and fiber-based temperature sensors have closedended sheaths that will not require any special processes for sealing. For these sensors, the feedthroughs seal around the outer diameter of the sheath. For the strain sensing fibers, the fibers must be sealed inside the sheath outside of the CVI containment, where temperatures are very low $\left(<100^{\circ} \mathrm{C}\right)$. For this, the fiber will be epoxied inside the sheath. 


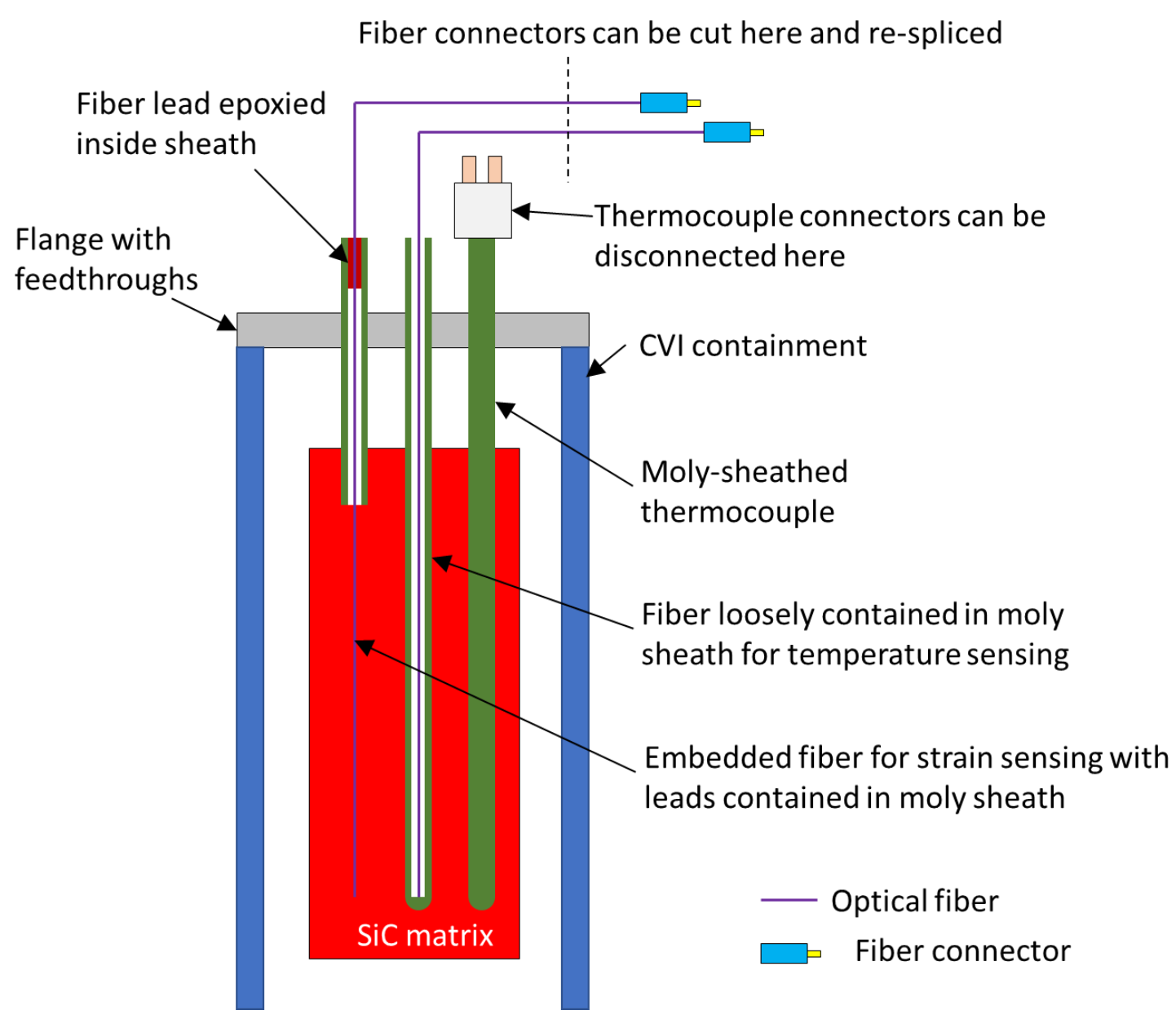

Figure 21. Test setup for embedding functional sensors in a SiC ceramic matrix.

\section{SUMMARY AND CONCLUSIONS}

This report describes the approach for embedding sensors in ceramic components for high-temperature nuclear applications. The sensors considered are thermocouples, SPNDs, spatially distributed fiber optic temperature sensors, and spatially distributed fiber optic strain sensors. The primary challenge for embedding these sensors is to identify sensors, or in most cases sensor sheath materials, that can survive many hours of exposure to $\mathrm{HCl}$ at temperatures of approximately $1,000^{\circ} \mathrm{C}$. Initial materials selection was guided by computational thermodynamics calculations and confirmed by testing the compatibility of samples embedded in a SiC using CVI. Characterization of the embedded samples revealed that W, Mo, and $\mathrm{Nb}$ are the most attractive sheath materials because they showed no significant reactions with $\mathrm{HCl}$ and minimal interactions with the surrounding SiC matrix. Ta was successfully embedded but showed significant silicide formation. Ni reacted violently during the CVI process. Au-coated fiber optic sensors showed what appears to be melting of the Au coating, but the $\mathrm{SiO}_{2}$ fibers otherwise appear to have been successfully embedded. The next step is to test functional sensors, which will initially include Mosheathed thermocouples, fiber optic temperature sensors, and fiber optic strain sensors. Future tests will consider Nb-sheathed HTIR TCs. 


\section{REFERENCES}

1. McCullough, C. R., Summary report on design and development of high temperature gas-cooled power pile, MonN-383, Clinton Labs: Oak Ridge, TN (1947).

2. Briant, R. C. and A. M. Weinberg, "Molten Fluorides as Power Reactor Fuels," Nuclear Science and Engineering, 2 (1957) p. 797-803.

3. Lee, W.-J., Y.-W. Kim and J.-H. Chang, "Perspectives of nuclear heat and hydrogen," Nuclear Engineering and Technology, 41 (2009) p. 413-426.

4. Section III Rules for Construction of Nuclear Facility Components: Division 5 High Temperature Reactors, in 2019 ASME Boiler and Pressure Vessel Code: An International Code. 2019, The American Society of Mechanical Engineers: New York, NY.

5. Ren, W. and R. Swindeman, "A Review on Current Status of Alloys 617 and 230 for Gen IV Nuclear Reactor Internals and Heat Exchangers," Journal of Pressure Vessel Technology, 131 (2009) p. 044002.

6. Goldstein, N. P. and W. H. Todt, "A Survey of Self-Powered Detectors - Present and Future," IEEE Transactions on Nuclear Science, 26 (1979) p. 916-923.

7. Wood, T. W., B. Blake, T. E. Blue, C. M. Petrie and D. Hawn, "Evaluation of the Performance of Distributed Temperature Measurements with Single-Mode Fiber Using Rayleigh Backscatter up to $1000^{\circ}$ C," IEEE Sensors Journal, 14 (2014) p. 124-128.

8. Cheymol, G., H. Long, J. F. Villard and B. Brichard, "High Level Gamma and Neutron Irradiation of Silica Optical Fibers in CEA OSIRIS Nuclear Reactor," IEEE Transactions on Nuclear Science, 55 (2008) p. 2252-2258.

9. Zaghloul, M. A. S. et al., "Radiation resistant fiber Bragg grating in random air-line fibers for sensing applications in nuclear reactor cores," Optics Express, 26 (2018) p. 11775-11786.

10. Petrie, C. M., D. P. Hawn, W. Windl and T. E. Blue, "Reactor radiation-induced attenuation in fused silica optical fibers heated up to $1000{ }^{\circ} \mathrm{C}$," Journal of Non-Crystalline Solids, 409 (2015) p. 88-94.

11. Petrie, C. M. and T. E. Blue, "In Situ Thermally Induced Attenuation in Sapphire Optical Fibers Heated to $1400^{\circ}$ C," Journal of the American Ceramic Society, 98 (2015) p. 483-489.

12. Wilson, B. A., C. M. Petrie and T. E. Blue, "High-temperature effects on the light transmission through sapphire optical fiber," Journal of the American Ceramic Society, 101 (2018) p. 34523459.

13. Petrie, C. M., B. Wilson and T. E. Blue, "In Situ Gamma Radiation-Induced Attenuation in Sapphire Optical Fibers Heated to $1000^{\circ}$ C," Journal of the American Ceramic Society, 97 (2014) p. 3150-3156.

14. Girard, S. et al., "Radiation Effects on Silica-Based Optical Fibers: Recent Advances and Future Challenges," IEEE Transactions on Nuclear Science, 60 (2013) p. 2015-2036.

15. Snead, L. L. et al., "Handbook of SiC properties for fuel performance modeling," Journal of Nuclear Materials, 371 (2007) p. 329-377.

16. Petrie, C. M. et al., "Embedded metallized optical fibers for high temperature applications," Smart Materials and Structures, 28 (2019) p.

17. Petrie, C. M., N. Sridharan, A. Hehr, M. Norfolk and J. Sheridan, "High-temperature strain monitoring of stainless steel using fiber optics embedded in ultrasonically consolidated nickel layers," Smart Materials and Structures, 28 (2019) p. 085041.

18. Petrie, C. et al., "Embedded Fiber Optic Sensors for In-Pile Applications," in 11th Nuclear Plant Instrumentation, Control and Human-Machine Interface Technologies. 2019: Orlando, FL, USA. p. 459-468.

19. Terrani, K., B. Jolly and M. Trammell, "3D printing of high-purity silicon carbide," Journal of the American Ceramic Society, (under review) p. 
20. Reed, T. B., Free energy of formation of binary compounds. 1971: MIT press.

21. Stull, D. R. and H. Prophet, JANAF thermochemical tables, National Standard Reference Data System: (1971).

22. Saunders, N. and A. P. Miodownik, CALPHAD (calculation of phase diagrams): a comprehensive guide. Vol. 1. 1998: Elsevier.

23. Rempe, J. L., D. L. Knudson, K. G. Condie and S. C. Wilkins, "Thermocouples for HighTemperature In-Pile Testing," Nuclear Technology, 156 (2006) p. 320-331. 